\title{
Mortuary metre
}

\section{Introduction: Horizontal stratigraphy in early Anglo-Saxon cemeteries}

Metre is a measurement of cadence, of narrative time, and this chapter examines the chronological construction of cemetery space, employing the latest chronologies based on a detailed discussion of artefact typologies, as well as the new chronologies proposed by John Hines and Alex Bayliss (2013), and Catherine Hills and Sam Lucy (2013). A number of key early Anglo-Saxon cemeteries have been selected to illustrate different sequential characters in order to illustrate common patterns seen in the chronology of early Anglo-Saxon cemeteries, many of which are visible elsewhere in this book. Investigating the development of cemeteries and the transformation of funerary display over time, this chapter is by necessity both detailed and complex, exploring dating down to the burial plot, the individual grave and the artefact, so that we can understand the development of burial plots and sites as a whole. This detail reveals the complexities of horizontal stratigraphy, so we can begin to understand the generational cadence that underpins the changing attitudes towards artefacts, mortuary technologies and styles.

Beginning with Spong Hill, Norfolk, we investigate the use of new rituals as part of continually evolving social dynamics. Other sites include Bossut-Gottechain in Belgium, Sewerby, Apple Down, Wakerley, Oakington, Deal and Orpington, followed by a substantial reinvestigation of the chronology and horizontal stratigraphy at Dover Buckland. This draws on the previous case studies examined in this chapter to present a coherent dissection of the chronology of multiple-grave plots, each of which used different mortuary technologies to present similar and dissimilar characteristics as part of localised mortuary expressions. Each of these plots had different architects, and each grave was attended by a unique assembly of mourners. The mortuary metre highlights discordant identities, and sets the pace of chronological change. 
As discussed in Chapter 1, traditional approaches to horizontal stratigraphy often expect adjacent graves to have comparable dates, and to have been positioned in sequential order. However, sometimes the fact that they were not adjacent in date is the important mortuary technology, in cases where mourners returned to particular spaces for generation after generation. In practice, most early Anglo-Saxon cemeteries were complex, with multiple changing variables, and many had no obvious initial single focus. As we have seen in Chapter 1, neither Finglesham, Kent nor Berinsfield, Oxfordshire, had a single early focus (Härke, 1992: 171). Both cemeteries actually exhibited multiple simultaneous chronological patterning. At Finglesham, some burials were placed at the edges of the cemetery, and others focused on key barrow burials so that these locations became chronologically specific focal points, a trend also seen at Dover Buckland and Oakington (see Chapter 2 and this chapter, below). Berinsfield did not have a single earlier focus either, but exhibited multiple areas of continued emphasis, where mourners returned to central areas throughout its sixth- and (short-lived) seventh-century use. Focal points rarely had one early date because they were visited and revisited, reinterpreted and represented throughout multiple generations and during different phases of activity. It is this reinterpretation that could refresh, or undermine, their importance for each subsequent generation.

Chapter 1 illustrated some chronological characteristics of Deal and Orpington that differed. Deal was organised around two plots which were returned to for generations, as well as a later group of graves. With these later graves the focus changed, and the earlier plots were altered and abandoned in favour of a new burial form. Grave location and individual groups of graves could have a chronological character, one plot following consecutively on from another. The burials at Deal consisted of two contemporary plots, or three groups of burials, which were separated around a single, large Bronze Age barrow. The two plots of graves were contemporaneous, part of a first phase broadly early and middle-sixth-century in date. Notably, however, some laterseventh-century graves truncated or partly obliterated earlier burials, and this seems to have been deliberate destruction, or the rewriting of the cemetery narrative by changing its aesthetic appearance and directing attention towards recently dead individuals rather than a long-deceased antecedent. It was part of a changing metre, with a new message, and the eastern group of graves was not a focused plot, but instead it was part of this second phase, dating broadly to the later sixth and seventh centuries. The character of these graves changed, placing new emphasis on groups of male-gendered weapon graves, a pattern also seen in a contemporaneous part of Dover Buckland. 
Orpington had one inhumation, grave 23, around which multiple male weapon graves were placed. These graves dated throughout the whole of the sixth century, but many were not contemporaneous. At this sixth-century site, the emphasis was on a single biologically male antecedent, grave 23, and this may have engendered in subsequent generations a desire to highlight their martial identity, because it was weapon graves which seem to have dominated this mortuary space. As the chronology shows, the individuals within these weapon graves were very young or not yet born when grave 23 was constructed. They could not have been a contemporary group of warriors, unlike those at Deal or Dover Buckland (see below). Instead, they consisted of several generations of men who empathised with, or wanted to express, a similar identity. This centre was created through the repeated use of a particular place to inter children and also men with weapons. The placement of later graves around this centre shows how it was used and how these graves then shaped and contributed to the construction of community narratives. Perhaps Orpington was eventually abandoned as a burial site by a generation who did not feel connected to a previously highlighted ancestor, or this new generation may have wanted to focus the burial of their dead on a different part of their identity. This is the narrative that this chapter highlights, difference in the pace of change and difference in the cadence of cemetery space, particularly focusing on internal plot dynamics. This chronological character provides a key in our concluding discussions in Chapter 6, when we start to put all of these spatial, material and chronological cemetery technologies together to understand the cemetery space holistically.

\section{Dating early Anglo-Saxon graves}

Sam Lucy suggested that the development of artefact typologies, and the detailed chronologies which often accompany them, was a distraction from the important question of social relations (Lucy, 1997: 151). Similarly, Hope-Taylor (1977), indicated a frustration with his peers' obsession with artefacts over social and organisational aspects of AngloSaxon cemetery studies, criticisms that still could be levelled at some contemporary projects. Importantly, however, studies that ask social questions benefit from a good understanding of details. For example, the dating of artefacts is an important part of understanding how that object was used, circulated and deposited, and it affects the way it might be interpreted (see Sayer et. al., 2019). We also need to understand who the living were, and how their experiences of cemetery space moulded their attitudes towards it. Who attended a funeral, and how did attitudes to the corpse, dress, material culture, gender and age change along with 
the context under investigation? The early Anglo-Saxons did not have one attitude, or a single approach, to community, death, burial or the corpse, but many, and these changed over time.

The early Anglo-Saxon period discussed in this book dates between the middle-fifth and the later-seventh or earliest-eighth centuries, a span of some 250 years. In the last 250 years Western societies have seen profound changes to gender and dress, and attitudes to the dead have undergone significant change as well, such as the secularisation of the deathbed and the funeral, and the adoption of cremation in the early twentieth century (Davies 2005; Walter 1994). Attitudes towards gender have changed substantially, so today women have the right to work, vote and own property, and are found in social spaces that would have been unlikely just one hundred years ago. Social attitudes to religion, and the use of religious spaces, have transformed profoundly, with the proliferation of nonconformity in the nineteenth century and the increasing secularisation of society in the twentieth (King and Sayer, 2011). How and where people live has changed, and sanitation rules and increasing home ownership have transformed the use of urban spaces completely. How, when and where we use formal attire has also changed generation by generation. Why, then, would we consider the early Anglo-Saxon period to be any less dynamic? We see profound changes within the period, for example, the decline in brooch and buckle wearing seen at the end of the sixth or beginning of the seventh century in female graves suggests changes to costume (Owen-Crocker, 1986; Walton Rogers, 2007). We also see the decline in cremation practice (Williams, 2002a), the adoption, or re-adoption, of Christianity and the rise of a new political elite in the form of local, then regional, kingdoms (Owen-Crocker, 1986; Arnold, 1997; Petts, 2011). As a result, it is very important to understand the context and fluctuation of change within mortuary landscapes. As this chapter aims to demonstrate, the pace of change was not always at the same speed from cemetery to cemetery, or even from grave plot to grave plot. To get at this pace, we must first understand how graves are dated, and explore the impact of new dating systems on cemetery chronologies.

\section{Multiple objects, different dating systems}

One of the challenges of producing cemetery chronologies in this period is a reliance on artefact typologies, and their associated chronologies, to date graves. Utilising artefacts as dating material is useful because similar artefacts are found in multiple graves in different combinations. As a result, objects can be compared to see a pattern, and this might be a group of artefacts which are repeatedly associated with each other and 
so must be contemporary. However, this is also challenging because of the different systems used by archaeologists to date objects. In addition, artefacts were portable and their use was open to individual or regional variations; for example, there are a number of heirloom objects which were old when buried. This complexity is compounded because there are several different systems for artefact dating in use among early medieval scholars. Early Anglo-Saxon artefact typologies often include a mixture of local comparison, comparison with continental equivalents where coin-dating evidence might be available, and/or art-historical methods which are used particularly for the presence of Salin style I animal art, or the emergence of Salin Style II, which occurred around AD 560-70 (Lucy, 2000b: 16-20; Evison, 1987). Some dating systems investigate single artefacts to understand their development and context, for example beads, buckles, shields or spears (Marzinzik, 2003; Brugmann, 2004; Dickinson and Härke, 1992; Swanton, 1973; 1974). Other dating systems investigate the range of objects found in a region, for example Tania Dickinson's (1976) study of the Thames Valley or Martin Welch's (1983) investigation of Sussex. Still others look at national assemblages to understand wider social phenomena, for example Stoodley's (1999) investigation of female graves, or Härke's (1992) investigation of weapon graves.

Alternatively, some studies set out to make national chronologies based on multiple selected artefacts, for example Hines and Bayliss' Anglo-Saxon Graves and Grave Goods (2013). By necessity, national systems use these regional- or artefact-specific studies to develop their methods, and these may differ. For example, Dickinson suggested that there were seven types of disc brooch, based on decorative elements, whereas Welch preferred to see four, based on the presence and/or absence of decoration, mainly stamps or ring-and-dot. Welch (1983: 57) preferred a predominantly fifth-century date with some examples of the brooch from the sixth century, whereas Dickinson (1976: 121) dated them between $\mathrm{AD} 450$ and $\mathrm{AD} 550$. Many typologies are based on the work of Nils Åberg (1926) and, like Barry Ager (1985); Richard Avent (1975); and Edwin Thurlow Leeds (1945), these tend to employ artistic styles to understand chronological change. As a result, these studies emphasise a changing character around the later-sixth century, whereas Kurt Böhner (1958), Elis Behmer (1939) and Wilfried Menghin (1974) analysed Merovingian material culture and based much of their dating on coins. This allowed Evison (1987) and others to build Anglo-Saxon chronologies, for example Evison's study of knives from Dover Buckland (1987: 113). Just like Dover Buckland's knives, some typologies were developed by cemetery excavators to make site-specific observations, and these could end up influencing national approaches, for example 
Hirst (1985) on annular brooches from the cemetery at Sewerby. Some systems can prove to be complex or hard to work with outside the specific investigation. For example, Michael Swanton's spears can be difficult to delineate or separate into groups based on measurements (Dickinson, 1976: 291-2; Hines and Bayliss, 2013: 163). In this section I explore individual artefacts and their use in dating. In subsequent chapters I use these artefacts to describe a series of cemeteries highlighting different chronological characteristics.

Hines and Bayliss' chronological framework project (2013) aimed to make a chronological system for the later-sixth and seventh centuries based on Bayesian statistics and radiocarbon dating. This was an important piece of work, but, unfortunately, it had limitations for early Anglo-Saxon cemetery projects. Traditional artefact typologies start in the later-fifth century and often end in the early or mid-seventh century as artefacts were less frequently deposited in graves. The radiocarbon-dating project was able to explore seventh-century chronologies further, but its earliest dates are in the middle-sixth century, and so there is little crossover with earlier artefacts. In fact, one of the most notable differences is that traditional cemetery chronologies depend upon brooches, whereas the Hines and Bayliss chronological framework project dates around twenty brooches with wide definitions, as, for example, bow brooches or round brooches. In this dating system the early brooch types, disc brooches or cruciform brooches, tend to have distinct middle-sixth-century dates, but we know they have antecedents in the later-fifth and early sixth centuries. In fact, because of the absence of brooches in the Hines and Bayliss study, the chronology of female-gendered artefacts has changed little from artefact-typology systems. Notable exceptions include the identification of composite or garnet disc brooches in the middle-sixth century, an earlier development than was previously believed. Importantly, for female-gendered graves, beads (a common object) provide the most compatibility between an artefact-typology system and the radiocarbon-based dating systems, and the later bead combinations broadly correlate Hines and Bayliss' dates with Brugmann's phases. Nonetheless, there are considerable differences between Brugmann's (2004) national study and her regional study based on Dover Buckland (Brugmann, 2012). For example, grave 376 at Dover Buckland has beads of group B2 and so in the national framework dates to AD 580-650, but in the regional framework this grave is placed within phases 5-7 or AD 650-750 (Brugmann, 2004; Brugmann 2012: 324, 355; see Appendix 1 for a list of differently dated graves).

Another good point of crossover between the typology system and radiocarbon-dating system are buckles, which are found in male and 
female graves, with some gender differentiation according to type, in particular Sonja Marzinzik's (2003) typology. This is more complex than Hines and Bayliss' (2013) dating system for buckles, but these two approaches complement each other well. Weapons, notably shields and spears, however, provide something of a problem. Traditional spear and shield typologies consist of a combination of form and measurements, while the Hines and Bayliss chronological framework places greater emphasis on dimensions, and in particular the proportions of particular characteristics - height, length and breadth for example. This is similar to the existing object typologies, but different enough that compatibility has become an issue. This is a particular problem when looking at fifthand sixth-century cemeteries because the earliest graves are identifiable using artefact types, and the middle-sixth-century and later graves have been dated using limited radiocarbon dating. As a result, the male and female chronologies behave differently. For example, based on an analysis of Dover Buckland (more below), there are thirty-six male-gendered graves which can be dated to within close-fitting margins, and similarly for fifty-five female-gendered graves (see Table 3.1). The male dating relies heavily on the Hines and Bayliss system and on buckles. Table 3.1 shows that this approach appears to bunch male-gendered graves to AD 530-60, over-emphasising the middle-sixth century.

Using Table 3.1 as a contingency table for a chi-square test, we can investigate this pattern statistically; chi-square is suitable for this $2 \times 5$ contingency table because there are two independent samples, and the expected values are greater than five. Nonetheless, the result is similar to that with Fisher's exact test. For this exercise the frequency of male-gendered versus female-gendered graves was attributed to four date bands between AD 450 and AD 650. The $p$-value for this chi-square test comes out at 0.009813 , less than 0.05 , meaning that the pattern we can see in this data is significant. Either there was an increased frequency of weapon burials around AD 530-60, or this method of dating the male-gendered graves bunches them in the middle-sixth century (see below). Notably, the weapon graves that were dated on the basis of buckles, using Brugmann's Kentish chronology (2012: 325-53), tend to be more evenly spread between dates. More weapon graves, eleven, are

Table 3.1 Datable graves from Dover Buckland's sixth- and seventh-century phases

\begin{tabular}{llllll}
\hline & AD 450-530 & AD 530-560 & AD 560-600 & AD 600-650 & Totals \\
\hline male & 4 & 23 & 5 & 3 & 35 \\
female & 12 & 11 & 7 & 9 & 39 \\
\hline
\end{tabular}


associated with the later-sixth-century or early seventh-century phases $3 \mathrm{a}, 3 \mathrm{~b}$ or 3 , than the middle-sixth-century phase 2 which has seven (see Appendix 1). Brugmann's correspondence analysis included the weapon graves. This incompatibility issue appears to be because different approaches use different assumptions, which are then used to date individual graves and their objects. For this national study of cemetery organisation, the male chronology used has relied heavily on Hines and Bayliss' approach, which has the advantage of the subdivision of the spearheads into finer date ranges, allowing for greater resolution than Swanton's typology (Swanton, 1973; 1974). However, at least for the earlier examples, we need to be cautious because there are only three radiocarbon dates associated with the earliest spears of types SP2-a2b2, SP2-b1a2 and SP2-b1a3 (Hines and Bayliss, 2013: 565-6). The Hines and Bayliss approach is just a beginning and a more detailed look at weapon chronologies would be welcomed to fine-tune the errors and explore the details more closely. Equally, associating more radiocarbon dates with earlier weapons and brooches, as well as exploring the regional distinctions, would be valuable, despite the radiocarbon curve plateau around the fifth and early sixth centuries.

By necessity, the dating system used in this book is a hybrid of artefact typologies and radiocarbon dating, for example Hines and Bayliss (2013). This system is described in detail in this chapter and uses 'gateway' artefacts, which can assist in the accurate dating of graves because they are associated with a specific date, or a range of dates. When these objects are identified in a grave, that grave should be associated with the same dates; the more artefacts there are in a grave, the more accurately it can be dated. These artefacts are outlined below. This section is necessarily detailed so that the errors and assumptions are visible, and so that the understanding of cemetery layouts can be adapted as the dating methods become increasingly sophisticated. In both the Hines and Bayliss' chronological framework (2013), and in the more traditional artefact-based dating systems, there are a few objects that prove most useful in exploring comparative dates.

The presence of a group 1 cruciform brooch, for example, would identify a grave as fifth century in date. A type I.12a-i buckle was in use for the whole of the early Anglo-Saxon period, but a type II.7 buckle, by contrast, is associated only with the second half of the sixth century, and it is unlikely to be found with a group 1 cruciform brooch - and, if it were, the brooch might be identified as an 'heirloom' object. It is also possible to separate graves into groups of a particular character, and this is done here where there are different areas of a cemetery that have distinct chronological characters. For this project, I am not approaching this with the formality of the stufe groups, like the phases or gravegood 
groups of Merovingian cemetery analysis (see, for example, Hines et al., 1999). Rather, I intend to show the different characters of particular graves to highlight cemetery specific trends or chronological differences between individual graves, or spatially associated groups of graves, where these are possible.

It is vital that we understand the chronology of individual graves, and of parts of cemeteries, so we may understand the interactions and decisions that contributed to site construction. There is a certain generational cadence, or metre, that is specific to each individual cemetery (Sayer, 2010). Some sites saw the development of new areas triggered by generational change. In others we see the regular refocusing of graves around a particular barrow or key ancestor, and in yet other cemeteries we see the same areas of a site or plot returned to repeatedly, presumably to bury particular dead, even where a new burial will obliterate a previous one. In this way some communities reinforced antecedents within the cemetery space, and some rewrote the space constantly, turning the mortuary landscape into a palimpsest. What is fascinating is that the same system was not always consistently used across one site, and nor was a single system necessarily used at all times in the life of a particular cemetery. This explains the apparent complexity of larger or more long-lived sites, such as Dover Buckland or Lechlade, which are both explored in more detail here and in Chapter 6 in this volume.

\section{Objects and their dates}

In this section I present the dating system used here and discuss how the new radiocarbon project changes our perspectives. I start with female-gendered artefacts, and then focus on male artefacts and gender-neutral objects, because the radiocarbon dates have a different impact on these groups of objects.

\section{Round brooches}

Disc brooches are flat-cast copper-alloy brooches which may have simple stamped decoration in the form of lines, dots or perforated edges; it is likely that they date between the fifth and middle-sixth centuries (Welch, 1983: 57; Dickinson, 1976: 121). Applied brooches, by contrast, are composite objects, which have a flat copper-alloy plate with a decorated disc of thin metal fixed to the face of the brooch. They have been split into three types, dated from the fifth century to late-sixth century based on the presence of decorative elements and animal style I or II art, called Salin style I or II (Welch, 1983; Dickinson, 1976; 1979). Saucer brooches have been studied by Dickinson $(1976 ; 1993)$ and are 
primarily a sixth-century type, with eighteen different groups characterised by abstract designs. Abstract decoration is followed by animal designs; larger, more elaborate types are dated to the late-sixth and early seventh centuries. Hines and Bayliss (2013: 367, 221) dated six saucer brooches and suggested that they have a chronologically distinct horizon in the middle-sixth century.

Button brooches have a rounded human or stylised face, and are around $19.8 \mathrm{~mm}$ in diameter. They were identified by Åberg (1926) and Leeds (1945), who placed them in the later-sixth century as a group; however, both Dickinson (1976) and Welch (1983) date them earlier than that, with a later-fifth-century date. There are twelve basic types, dating broadly within the fifth and sixth centuries. Avent (1975) produced the only typology of composite or garnet disc brooches. $\mathrm{He}$ divided them into four groups: keystone brooches (late-sixth to early seventh century); plated brooches (early seventh century); composite brooches (early to middle-seventh century); and a miscellaneous group. However, the dating for these is problematic because it was based on limited numbers of objects and on art-historical rather than contextual comparison. Hines and Bayliss' dating of these objects places the BR2-1/b2 keystone brooches squarely in the mid-sixth century (Hines and Bayliss, 2013: 367, 221).

Annular brooches are common, varied but usually plain, and they defy conventional classification (Hines, 1984: 260-9; Penn and Brugmann, 2007: 25). The only real attempt to classify these brooches into chronological types was carried out by Sue Hirst (1985: 55-7), in her report on Sewerby. She separated them into two types, earlier flat-section or hammered, and later round- or D-section cast brooches, and divided these into subcategories based on decoration. Hirst then dated them around the early, middle or whole of the sixth century, with one seventh-century-type in the case of type VII, which had a bird- or animal-headed decoration. The radiocarbon-dated forms reported by Hines and Bayliss are comparable with this model (Hines and Bayliss, 2013: 367). Cognate brooches were identified by Leeds (1945), with a limited regional distribution, and date to the sixth century. Penannular brooches are similar to annular brooches, but have terminals and are also flat or D-section. These brooches have pre-Roman origins and some of the types which Elizabeth Fowler identified as Roman are found in Anglo-Saxon graves, used as bracelets (Fowler, 1960; 1963). Type G brooch typologies were substantially revisited by Dickinson (1982), who dated them broadly to the sixth and seventh centuries, and type $\mathrm{H}$ ranges from the mid-fifth to the eighth century. The quoit-brooch style is characterised by its zoomorphic and geomorphic elements and is primarily mid- to late-fifth century (Ager, 1985); some heavily worn 
examples come from early sixth-century contexts (Welch, 1983). Seiichi Suzuki carried out a more recent investigation of these objects but did not question the existing chronology (Suzuki, 2000).

\section{Long/bow brooches}

Cruciform brooches are derived from a Scandinavian brooch style. They were split into five types by Åberg (1926: 33-4) on the basis of stylistic elements, and this was further developed by Leeds (1945), Leeds and Pocock (1971), Mortimer (1990) and Martin (2015). They date from the early fifth century and continued with the later florid types to the mid-sixth century. Small-long brooches were first classified by Leeds (1945: 5), but have not seen any more comprehensive study. Midland (or mid-Anglian) examples may be sixth-century (Hirst, 1985), although Dickinson (1976: 174-82) regarded the Wessex examples as having a late-fifth-century origin. Welch (1983) dated the Sussex examples from the fifth to early sixth centuries. Great square-headed-brooches are elaborate gilt objects influenced by Scandinavian designs, and Leeds (1949) classified these by shape; however, Hines $(1984 ; 1997)$ has reclassified them into three phases, dating the first two to the early sixth century and the last, and most common, type to the mid-sixth century. The great square-headed-brooches dated by Hines and Bayliss (2013: 367) were of the sixth century. There is no agreement about the date of small square-headed brooches which may fit best into the first three quarters of the sixth century (Leeds, 1949; Leigh, 1980; Welch, 1983; Dickinson, 1976; Brugmann, 1999: 35; Hines and Bayliss, 2013: 367). There are two types of equal-armed brooches: imported types from the fifth century, and early sixth-century copies, which are mainly found in East Anglia (Evison, 1977; Hines, 1984; Bruns, 2003). Likewise, supporting-arm brooches were imports from what is now northern Germany or Holland, and date to the later-fifth century (Evison, 1977). Bird and animal brooches are also rare and were imported from the Middle Rhine Valley or Frankish areas; the Mill Hill (Deal, Kent) examples are early sixth-century or more 'advanced' sixth-century (Parfitt and Brugmann, 1997: 44-5).

\section{Other jewellery items}

Beads are a common find in the burials of women and children, and are a critical component of the chronology of child and female graves (Hines and Bayliss, 2013: 203). There have been various attempts to date them, all of which recognise the importance of colour combinations (Chadwick Hawkes, 1973; Guido, 1999). Brugmann (2004) tightened 
up these categories and produced the most comprehensive study of glass beads. She dated combinations of beads according to three groups, A, $\mathrm{B}$ and $\mathrm{C}$, which are in turn subdivided according to specific details: the presence of Roman types; biconical types; melon beads; polyhedral beads; or, in the later groups, the presence of white beads, dotted beads or annular twist beads. Brugmann's glass-bead chronologies are supported by Hines and Bayliss, with individual beads identified in the radiocarbon project fitting broadly with Brugmann's groups (Hines and Bayliss, 2013: 203-8). This correlation with the radiocarbon-dating project means they are one of the most reliable ways to date the graves of children and females. Beads provide a good crossover with the artefact-dating methods. In short, by relying on beads as a 'gateway' object the two systems become reasonably comparable.

Amethyst beads are found in relatively controlled contexts, and Helen Geake (1997) placed them at the end of the sixth century and into the third quarter of the seventh century, or Brugmann's group B. Cowrieshell beads fit into Brugmann's group C (Hines and Bayliss, 2013: 208). Rock-crystal beads have not been the subject of a detailed study, but Dickinson (1976: 206) suggested that they tend towards a sixth-century date. Pendants come in a variety of forms; bracteates, for example, have been studied because of their Scandinavian connection, and many English example are copper or silver, not gold. Mogens Mackeprang (1952) identified five classes and Marit Gaimster (1992) argued that they may have been in production for just two or three generations during the sixth century. Despite this, she proposed that the five groups fitted between the fifth and seventh centuries. Hines and Bayliss (2013: 365) indicated that PE2-a,d,e and PE2-b were sixth-century scutiform pendants, but they may also be earlier. The PE4 lunulate, PE5 cross pendant and PE11 suspended bead are seventh-century, but these dates are based on a small number of examples (Hines and Bayliss, 2013: 211-15, 364). These silver scutiform pendants, identifiable because of their central boss, were previously dated to the sixth century (Hirst, 1985: 70). Those with cross decorations may be of the late-sixth to seventh centuries (Hines and Bayliss, 2013: 365). Other pendants include gold disc pendants, bullae pendants, wire ring pendants, cabochon pendants and cloisonné-work pendants, and these mostly date to the seventh century (Dickinson, 1976: 200-1; Geake, 1997: 36-7).

Ornate pins and linked-pin sets tend to be dated to the seventh century, but unfortunately singular or plain pins remain largely undated despite the attempts of Welch and Dickinson (Owen-Crocker, 1986: 90-3; Welch, 1983; Dickinson, 1976: 193-7). Indeed, the only pin identified with a distinctive signature by Hines and Bayliss (2013: 370) was the P12-a linked pin, which confirmed a seventh-century date. 
There is no agreement on the dating of bracelets because they vary so much between individual objects. They may have been most popular in the sixth century, with some decorated examples from the seventh (Dickinson, 1976: 200-1; Evison, 1987: 86; Hines, 1997: 268; Kennett, 1970: 27-8).

\section{Personal equipment}

Buckles are functional and decorative objects. Evison (1955), Chadwick Hawkes and Dunning (1961) and Geake (1994) all contributed to a patchy framework based on the presence of Salin type I and II animal art. However, the most comprehensive study is that of Marzinzik (2003), who started by dividing the buckles into groups with and without back plates. Subgroups were then based on the shape of elements which made up the buckle, and included the plate, tongue and decoration on the loop. As with beads, Marzinzik's buckle typology is based on continental chronologies, and Hines and Bayliss (2013: 332) agree that this relative sequence is plausible. They suggested that their first phase, BU2-d/BU2-h (AD 505-64), is followed by, second, BU3-a, BU3-g with BU3-c (AD 480-570), then third BU3-c, BU3-h, BU4-b and BU4-c (AD 570-650) followed by, fourth, BU3-d plus BU3-i (AD 610-80) and fifth and finally BU3-f (AD 635-710), presenting five abutting phases, a similar but simpler version of Marzinzik (2003). Buckles are less common in female graves of the seventh century (Owen-Crocker, 2004: 143; Walton Rogers, 2007: 187-9). Interestingly, one type, the BU8 (or Marzinzik type I.9-11), a simple oval-looped buckle dating AD 510-65, was probably placed in female graves a generation or so after it was placed in male graves (Hines and Bayliss, 2013: 245).

Hines (1993) made the most comprehensive study of both the chronology and typology of wrist clasps. Clasps have a chronological distribution between the fifth and seventh centuries, but are found most frequently and with the greatest diversity in the sixth century. Type B7, the most common form in England, was simply two plates, one with a hook and the other with a hole, which would have been sewn into the garment, and is a sixth-century type. Type B13a is similar, but each half of the clasp consisted of two elements, often a plate and bar, and is a late-fifth to early sixth-century form. David Brown (1977) published the only major corpus of firesteels, dividing them into three major groups based on decoration: bird-headed; horse-headed; and plain iron. Bird-headed examples, including the Portchester type, are probably fifth century, while horse-headed examples seem to be largely fifth- to latesixth-century, and the plain iron ones are undated. Girdle hangers are bronze T-shaped or open-worked key-like objects, some with impressed 
decorative elements on them; they date to the sixth century (Chadwick Hawkes, 1973; Hines, 1997; Hines and Bayliss, 2013: 370). Chatelaines are more elaborate girdle hangers, with a mixture of objects hanging from a chain or loop, which date from the sixth and seventh centuries (Chadwick Hawkes, 1973; Felder, 2015). Most cosmetic items are not reliably dated, for example, tweezers (Dickinson, 1976: 220-4; Hines and Bayliss, 2013: 370). However, combs of the fifth and sixth century are double-sided, whereas seventh-century combs are single-sided (Dickinson, 1976: 216-19). Hines and Bayliss (2013: 370) suggest that combs do not appear in early Anglo-Saxon inhumation graves until the later-sixth century. However, a recent dating project at Spong Hill, Norfolk, showed that triangular-topped combs from cremations are likely to appear in the fifth century (Hills and Lucy, 2013: 108).

\section{Weapons}

Swords are composite items and it is the pommel, scabbard, guard and decorative elements which can inform us about type and date (Bone, 1989: 63; Cameron, 2000: 11-12). The blades themselves remain consistent, fitting into Behmer's (1939) Merovingian schmal-blattig or narrow-bladed type. Menghin's (1974) sword typology, based on pommels and scabbard fittings, places English blades into three types, dating to the fifth century, the early sixth century, and from the fifth to the middle of the sixth century, respectively. Hines and Bayliss (2013: 332) suggest two overlapping sequences broadly equivalent to Menghin's, but unfortunately only the SW4, equivalent to Menghin's C, D and E, had enough radiocarbon dates to be reliably dated. Swords probably came into use as gravegoods between AD 420 and AD 560 and had gone out of use by AD 650 (Brunning 2019). Hilt and guard types have been studied by Behmer (1939) and Menghin (1974) for the fifth and sixth centuries, whereas those of the eighth century and beyond have been looked at by Dunning and Everson (1961), Evison (1967) and Wilson (1965). Evison (1967: 67) looked at a number of sword rings and observed that the mobile rings were earlier, while later ones had been fused to the hilt. Other paraphernalia, such as pyramids and strap-holders, are of the seventh century, and have been discussed in detail by Rupert BruceMitford (1978), and Hines and Bayliss (2013: 183-9). Despite dates for some parts of swords, swords remain difficult to date, probably because of their role as heirlooms, meaning that old swords can be found in later graves (Dickinson, 1976; Härke, 2000b; Sayer et al., 2019; Brunning, 2017; Brunning 2019).

Spearheads have been studied in detail by Swanton (1973; 1974), who grouped the typologies loosely on the profile, section, blade 
length and socket length/blade ratios of individual blades. His types are simply: A-B, Germanic derivative forms (A being barbed and B including spikes and mid-ribbed examples); C, leaf-shaped blades with the socket shorter than the blade; $\mathrm{D}$, leaf-shaped blades with the socket longer than the blade; E, angular straight-sided blades with the socket shorter than the blade; F, angular straight-sided blades with the socket longer than the blade; $\mathrm{H}$, consisting of distinctively concave-bladed spearheads (including H2, the most common Anglo-Saxon spearhead); I and $\mathrm{J}$ types, which have corrugated blades; and $\mathrm{K}$ and $\mathrm{L}$ types, which have fullered blades. Several criticisms have been levelled at this typology; for example, minor uncertainties create considerable ambiguity (Dickinson, 1976: 291-2; Hines and Bayliss, 2013: 163). Hines and Bayliss' chronology (2013) is based on Karen Høilund Nielsen's typology, which uses ratios of blade length and width, a system which separates spears by profile (Hines and Bayliss, 2013: 16880). Four types of spearhead - SP2-a2b; SP2-a2c; SPTip-212; SP2-a1a2; and SP2-b1a3 - fall at the start of the sequence, and probably date to the early and middle decades of the sixth century or earlier (Hines and Bayliss, 2013: 335). Types SP1-a3 and SP3-a fall into the second half of the sixth century, types SP1-a4 and SP4 have longer currency in the later-sixth and seventh centuries, and SP2-a2d and SP2-a1b1 appear to be restricted to the first half of the seventh century, but samples of these two types are limited (Hines and Bayliss, 2013: 336). In comparison with Swanton's, this system tends to put early spearheads into the midsixth century, but usefully it divides up the E-type with straight edges and $\mathrm{H}$-type, broadly the SP2-bs with concave sides, into different dates based on the widest point on the blade.

Dickinson and Härke (1992) produced a typology for shield bosses and they identified: carinated, modified, derivative-type, 'transition', Merovingian, low-curved and sugar-loaf bosses. The first three are fifth- and early sixth-century types. Merovingian bosses and low-curved bosses are broadly sixth-century types, while sugar-loaf are later-sixthand seventh-century. These forms are broadly based on the size and height of the boss, the width of the flange and the number of rivets on the flange. Hines and Bayliss' study identified five types of boss, SB1-5, where SB3 dates to the middle decades of the sixth century and SB4 is found in the decades around AD 600: AD 560-90 with probability of 68 per cent - AD 585-620, probability 68 per cent (Hines and Bayliss, 2013: 247-8, 334). Phyletic seriation produces a model that sees evolution from short to tall shield bosses. Shorter bosses $(<130 \mathrm{~mm})$ are earlier than taller bosses $(>130 \mathrm{~mm})$ and wider flanges $(>17 \mathrm{~mm})$ are earlier than smaller flanges $(<17 \mathrm{~mm})$, with the transition around AD 565-85 (Hines and Bayliss, 2013: 249-50). 
The last weapon discussed here is the seax, which was a heavy, single-edged bladed weapon larger than most knives (Gale, 1989: 71). There were three main types of seax in early Anglo-Saxon England: the narrow seax, divided into triangular-bladed, small and large; the broad seax; and the long seax (Böhner, 1958: 135-45; Dickinson, 1976). Seaxes were a sixth-century innovation, first appearing around AD 525-60, but predominantly dated to the seventh century as swords declined in frequency. Phyletic seriation sees an evolution from smaller $(<310 \mathrm{~mm})$ to longer $(>310 \mathrm{~mm})$ seaxes around AD $600-35$ - probability 68 per cent (Hines and Bayliss, 2013: 248-9). Their use as gravegoods ended around $\mathrm{AD}$ 670-705 and the radiocarbon dates are in broad agreement with continental parallels (Hines and Bayliss, 2013: 334).

\section{Vessels}

Donald Harden $(1956 ; 1978)$ studied both Roman and Anglo-Saxon glass vessel types, including: stemmed beakers, claw beakers, cone beakers, horns, bell beakers, bag beakers, pouch bottles, squat jars, bottles, palm cups, bowls and buckets. Evison studied claw beakers and the Kempston-type cone beakers (Evison, 1972; 1982). As a result, glass vessels have been placed into three set date groups: fifth to early sixth century, sixth century or seventh century. Jean Cook (2004) produced a corpus of sixty-two copper-alloy-bound and twenty-four iron-bound buckets and fitted them into phases on the basis of an individual bucket's association with other gravegoods. Unfortunately there is no clear-cut typology. Nowell Myres' typology $(1969 ; 1977)$ still stands as the only way to date Anglo-Saxon pottery, despite being very problematic and hard to repeat (Chadwick Hawkes, 1974; Morris, 1974). He split the corpus into several groups on the basis of quite generic shapes: biconical, globular, shouldered, necked, and bulbous or wide-mouthed. $\mathrm{He}$ dated other aspects as well, including handles, lugs, bosses and stamped decoration. The only significant addition is Evison's chronology (1979) of wheel-thrown pottery and continental wares.

\section{Cemeteries' chronologies}

The early Anglo-Saxon cemetery at Spong Hill, central Norfolk, was first excavated in 1968 and then systematically between 1972 and 1975 (Hills et al., 1984: 32). It was a mixed-rite site with over 2500 cremations and fifty-seven inhumation graves. Antiquarian investigators may have removed many hundreds of cremations but, nonetheless, its large size means that much of the internal chronology can be understood (Hills and Lucy, 2013). The earliest cremation graves at Spong Hill, 
phase A, started around or just before the mid-fifth century, and the key artefacts used to date the site included antler combs and cruciform brooches. The latest phase, phase $\mathrm{C}$, consisted of cremation and inhumation graves. This relative chronology led Catherine Hills to conclude that the majority of the cremation graves were deposited in the fifth century (Hills and Lucy, 2013; Hills, 2017: 248-50). Like other sites we have discussed, Spong Hill was neither a monocentric, nor a polycentric cemetery, but rather it had phases which changed between a single focus and multiple foci.

There were essentially two significant chronological changes. Phase A cremations and pottery stamps had a particular concentration on the south of the site (Figure 3.1) but were also found across the whole space. Phase A/B cremations were equally dispersed, but perhaps concentrated in the south of the cemetery, just to the east of the phase A burials. Significantly, in phase B, the southern part of the cemetery remained a focus for burial, but cremation urns became much denser across three areas more to the north of the site (Figure 3.2). Notably, in phase C, the cremations shifted their focus to the north-east of the site in between the contemporary inhumation graves (Figure 3.3). Unfortunately, large numbers of cremations, particularly from the middle spaces of Spong Hill cemetery, are not currently datable (Hills and Lucy, 2013).

Nonetheless, Spong Hill highlights the challenges presented by horizontal stratigraphy: instead of burial location changing from one place to another, it persisted in the southern part of the cemetery across phases A to C, although with significantly less emphasis in phase C. The southern area remained an important focus, returned to for over a hundred years or so. Several generations chose to bury their dead among the urns of their antecedents. The phase B cremations saw burial in existing areas continue, but significant new foci developed in the north. However, it was not until phase $\mathrm{C}$ that the focus and style of burial saw significant change. In phase $\mathrm{C}$, burial persisted, but this phase saw the rejection of previous foci and the establishment of a new central location within which to bury cremations. At the same time, the introduction of inhumation burial was a break from the past, a recreation of burial practices according to a new narrative which took the previous mode and reinvented it. The physical proximity of the existing cemetery space remained important. Despite the change in style, a connection to the original cemetery seems to be part of why new graves were located within this space, and not within a new cemetery.

There are examples of sites which seem to maintain a single focus, even if they developed using different organisational methods. BossutGottechain is a good example of a chronologically concentric site. Bossut-Gottechain is a Merovingian cemetery located in the province of 

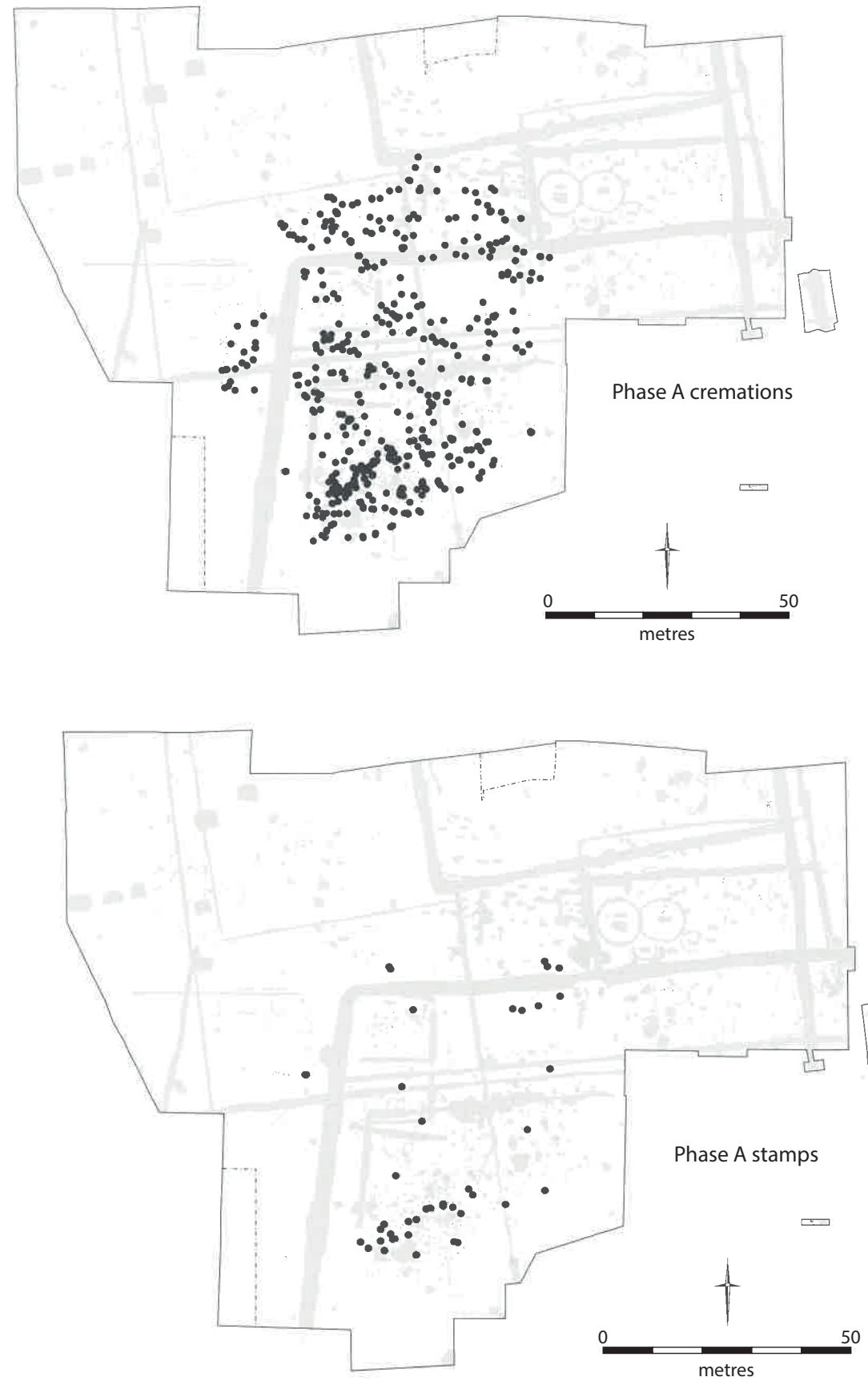

Figure 3.1 Spong Hill, Norfolk: phase A cremations and phase A stamp groups, showing the southern concentration of cremation urns. 

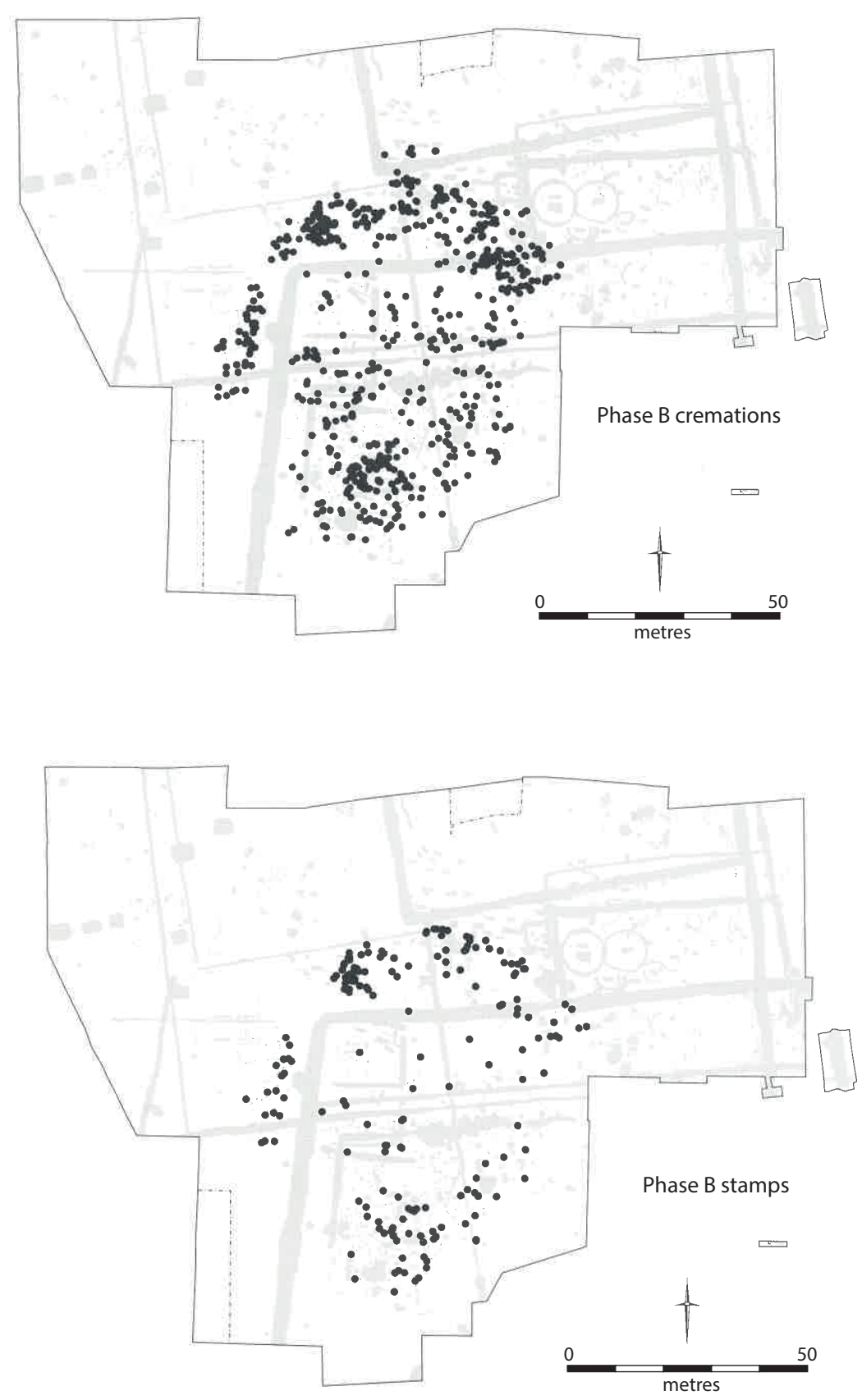

Figure 3.2 Spong Hill, phase B cremations and phase B stamp groups, showing the concentration of cremation urns around the whole area. 

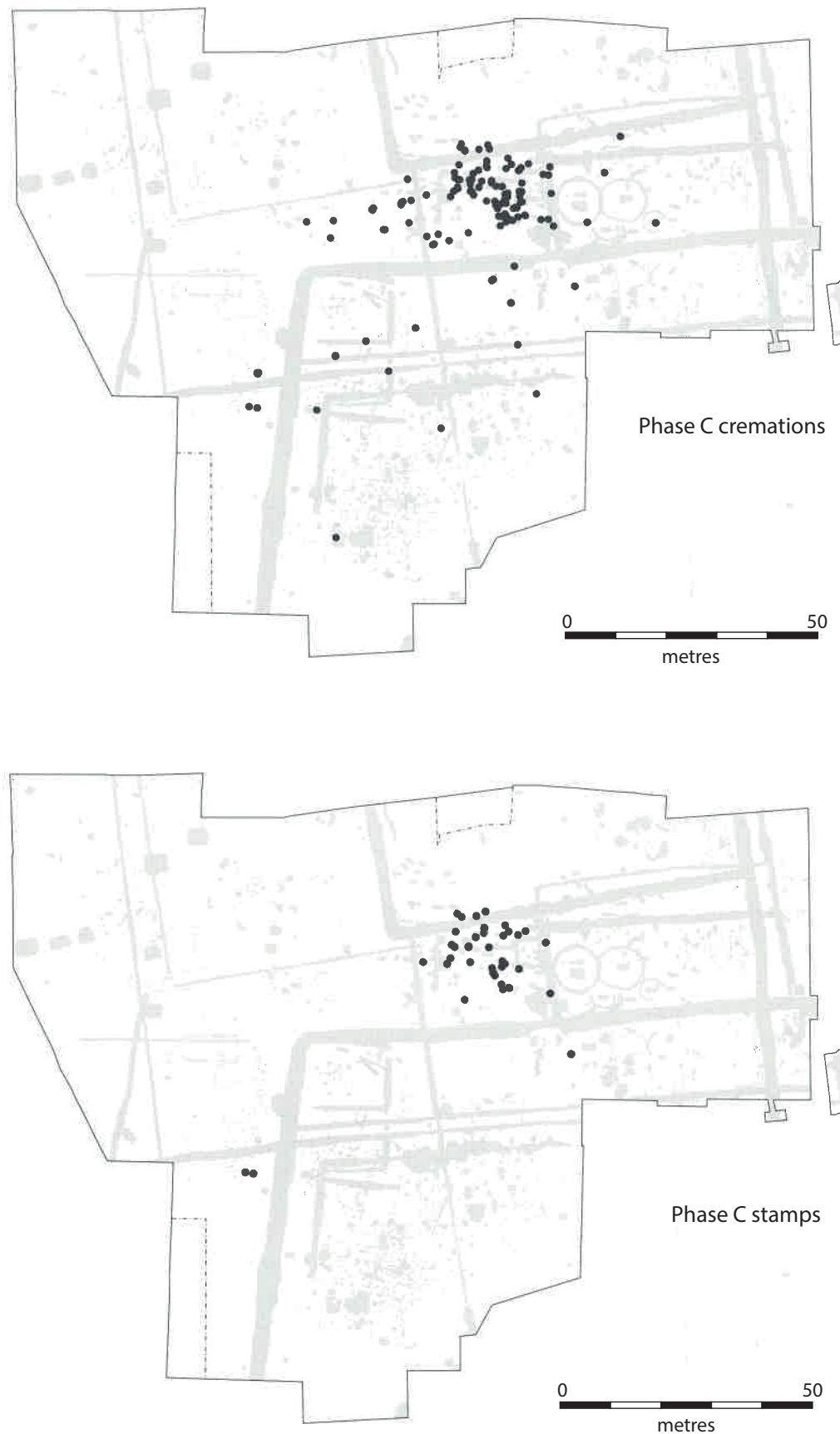

Figure 3.3 Spong Hill, phase C cremations and phase C stamp groups, showing the northern concentration of cremation urns, and the tighter clustering in this phase. 
Brabant, $30 \mathrm{~km}$ south-east of Brussels, and was excavated between 2003 and 2006 in advance of road construction (Vrielynck, 2012). The excavated site consisted of 436 graves, but some were lost due to tree planting or surface erosion. It was in use for 180 years, from the last quarter of the fifth century to the middle of the seventh, making it contemporary with the early Anglo-Saxon cemeteries described elsewhere. The chronological assessment discussed here was developed based on some 8,300 beads from the site (Vrielynck, 2012). Notably, Bossut-Gottechain had a core of early burials (late-fifth century) on a roughly N/S orientation or a contrasting E/W orientation (Figure 3.4). On the edge of the earliest burial area had been placed a single horse grave. The early burials

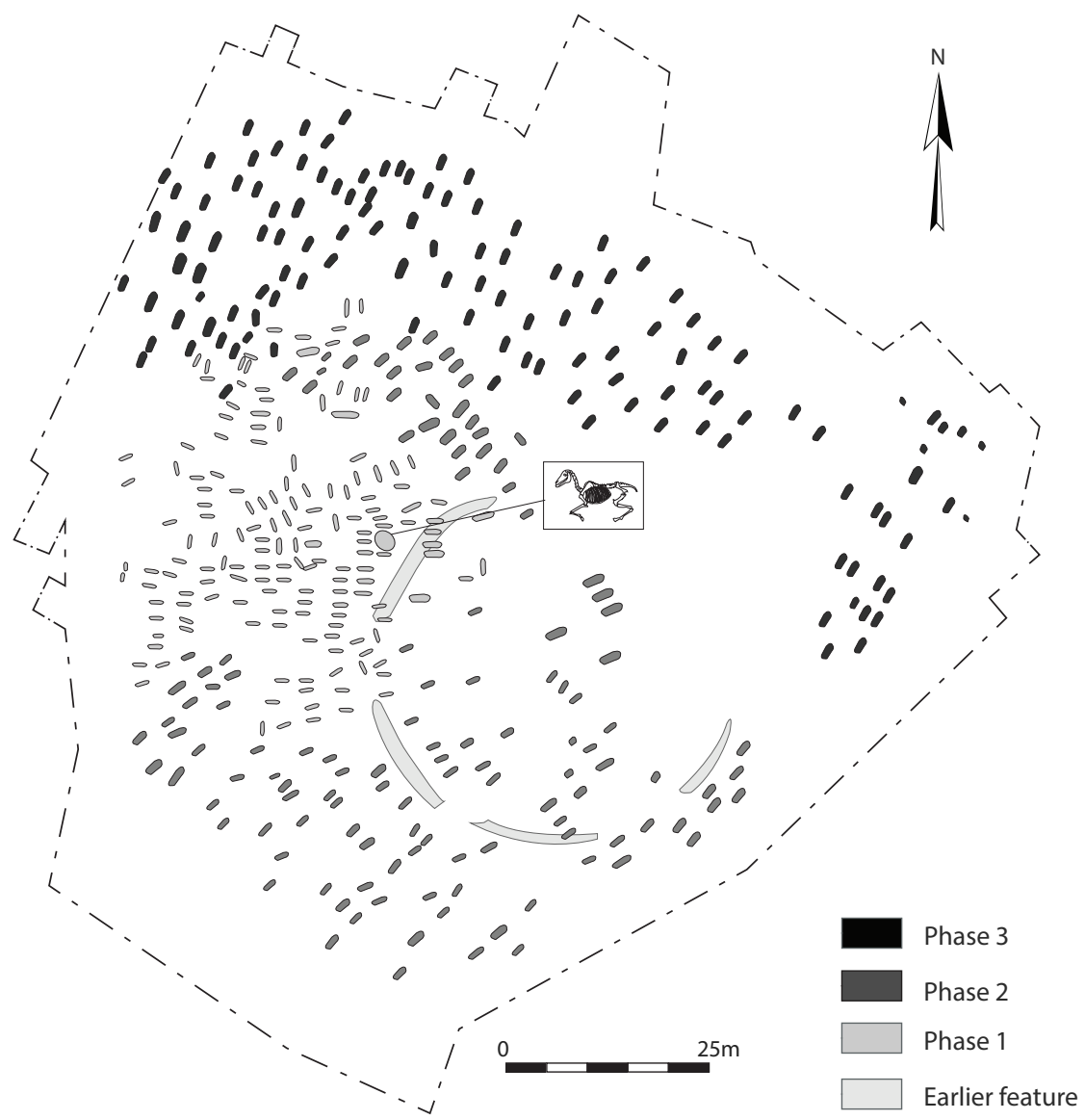

Figure 3.4 Bossut-Gottechain was a Merovingian cemetery with three distinct phases. A core of early inhumations was surrounded by increasingly ordered burials. 
were described by the excavators as phase-one burials (Vanmechelen and Vrielynck, 2009) and showed a contrasting orientation, which distinguished burials within the fifth- and sixth-century area from the more regular later graves. Some twenty-one graves in the central part of the cemetery were on a N/S orientation, whereas the surrounding graves were E/W. This created an aesthetic contrast within the space, intercutting was limited and so presumably the graves were marked in some way and were visible. In the second and third phases orientation was used in a different way, and did not serve to highlight individual burials. The phase-two and three burials from the late-sixth and seventh centuries were interred on a NE/SW orientation, highlighting or creating a difference between them and the phase-one inhumations. This orientation created a deliberate contrast and was an important aspect of the aesthetics of the cemetery space. In this case, the orientation served two purposes. In the phase-one burials it distinguished particular inhumations. In the first few years, these newly NE/SW burials would have been noticeably at odds with the more numerous earlier inhumations. The phase-two graves were more widely spaced, regular and more ordered; indeed, from the cemetery plan they appear to be organised into rows. By the time of phase three, this ordered aesthetic had become the dominant visual form, with the smaller, more chaotic, phase-one area providing a contrasting visual experience. Nonetheless, phase-two and three burials wrapped around phase-one burials, 'foregrounding' them as the historic core of the site (Vanmechelen and Vrielynck, 2009). Despite the contrast the phase-one burials remained important to the successive community and contributed memories, mnemonic narratives and aesthetic qualities. This contrasting orientation at Bossut-Gottechain was deliberately cultivated and, like the spatial change in the later phases of Spong Hill, it must have helped contribute to the creation of an ancestral other, perhaps giving the impression that 'we are from them, but we are different to them'.

Interestingly, Sewerby, East Yorkshire, may also have had a chronological character to its organisation. The cemetery was first identified in 1958 during the building of a new farmhouse; following initial sampling work two preliminary excavations ensued in 1959 and 1974, but the site was not completely excavated. The excavated cemetery consisted of fifty-seven inhumations and was an exceptional find at the time (Hirst, 1985: xvii-17). As already discussed, Sewerby had no obvious differentiation by grave orientation, and statistical assessment showed spatial homogeneity, meaning there appears to have been no deliberate clustering (Chapter 2). Nonetheless, Sewerby had a structural component. This component was most evident in the earliest burials and, because of this, we must rely on artefact typologies, namely brooch, bead and buckle typologies, to help in our understanding of it. The artefact chronologies 
suggest three different groups, consisting of a core area with two later groups on either side of this.

The excavated area at Sewerby seems to have had a core of earlier burials; the datable graves that make this up consisted of inhumations 8,12 , 17, 28 and 45. Burial 8 was interred with beads of Brugmann's A1-type combination, and a cruciform brooch of the $\mathrm{C} 2$ type, and two undated annular brooches (Brugmann, 2004). Consequently, it is suggested that grave 8 had an early sixth-century date, although the cruciform brooch may suggest that burial came at the end of this range. Similarly, burial 12 included an A1 bead combination giving it an early date, with small-long and cruciform brooches of the Mortimer D2 and B2 variety, which suggest an early sixth-century date (Mortimer, 1990; Martin, 2015: 124). Burial 17 contained annular brooches and an A1 bead combination, also placing it in the early sixth century. Grave 28 had a cruciform brooch of the D2 type, and an A2 bead combination which overlapped somewhat with the A1 in the early sixth century, a date which fits the brooch.

To the north-east of these early graves was a series of later ones -15 , $19,35,38$ and 50.1. These post-dated the core burials and had associated artefacts consistent with a broadly mid-sixth-century, or slightly later, date. These included grave 15 with annular IV and cruciform C2 brooches, wrist clasps of the B13a and B18 type, and a buckle of the common I.12a-i type. Notably, there was also a string of beads of the A2 combination. Grave 19 had annular IV brooches, a great square-headed brooch of type XXII, beads of the B1 combination, and buckles of the I.5a and II.17 type. Grave 35 had annular IV brooches, a cruciform brooch of the $\mathrm{B} 3$ type, common $\mathrm{B} 7$ wrist clasps, and a silver scutiform pendant, beads of the A2b combination, an I.12a-i buckle and a girdle-hanger. This area also included two burials, 38 and 50.1, unfortunately datable only broadly to the sixth century but which may be contemporary with each other: grave 38 had an annular IV brooch, B7 wrist clasps and a pendant. Grave 50.1 included an annular IV brooch and common B7 wrist clasps (Figure 3.5).

To the south of the early graves there was a series of much later ones, with a later-sixth-century, or potentially even early seventh-century, character. These included grave 16 with wrist clasps of type B18 and a type B bead combination, and grave 23 with annular IV brooches and buckles of types I.2 and II19a, as well as part of a small metal chain similar to one from grave 24 . Grave 24 also contained a Salin animal style II silver penannular brooch with bird-head terminals. Hirst placed graves 23 and 24 in the seventh century (Hirst, 1985: 95), but animal art of style II can date to the later-sixth century, and the character and location of these graves is more congruent with a sixth-century date. Grave 49 also suggests a later-sixth-century date and contained over 200 beads, 

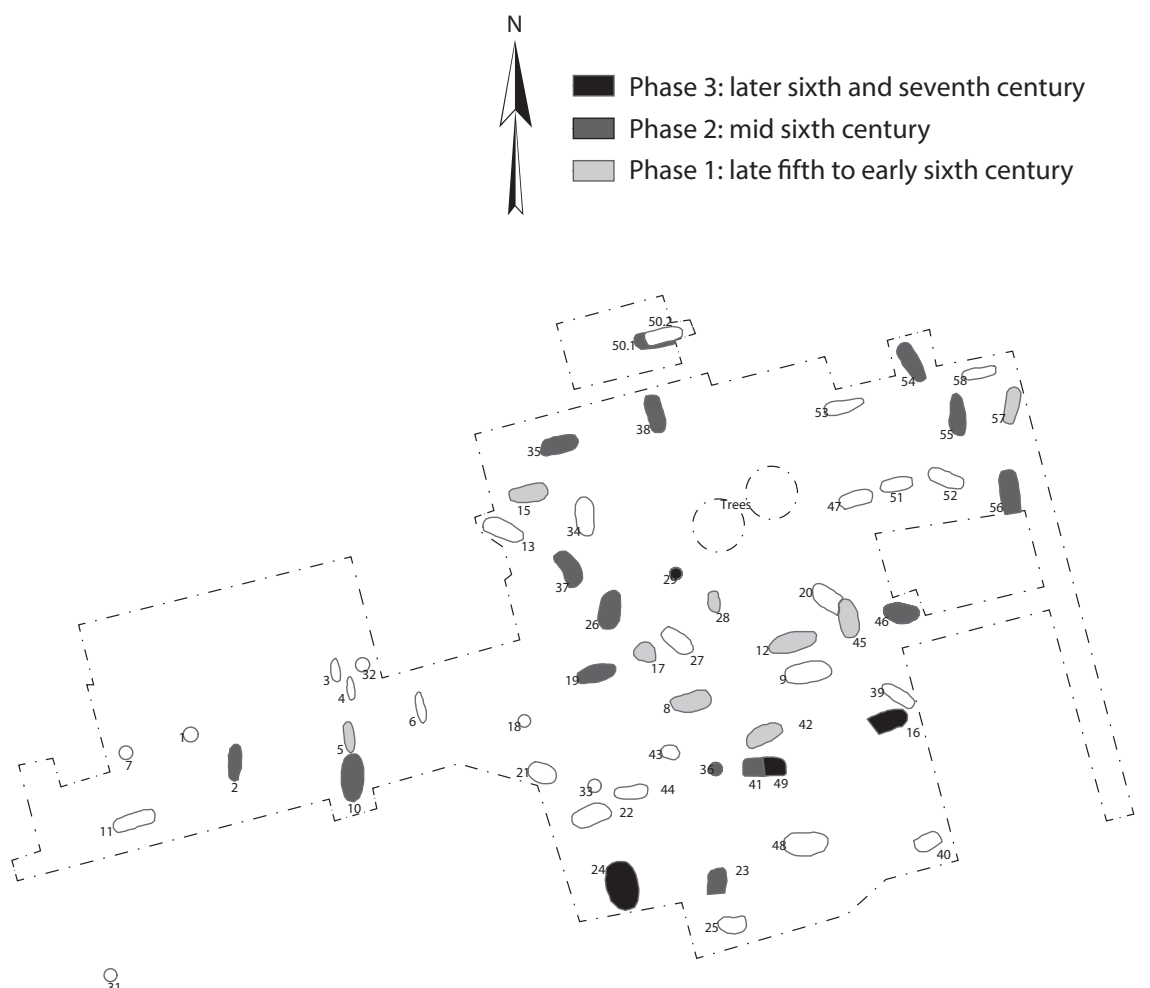

Figure 3.5 Sewerby, the distribution of datable graves.

two small-long brooches, a cruciform brooch of type C3, wrist clasps of the B18 type, a bronze cauldron/vessel and a girdle-hanger. Overall, these later graves show a greater diversity in the range of associated objects identified than in the previous two phases.

These three phases of graves were about the same size, and were buried in different places in a concentric organisation (Figure 3.6). The early sixth-century core area consisted of eight or nine graves, adjacent to which was a mid-sixth-century area of similar size. The later-sixth- or early seventh-century area is to the south. Each of these three areas contained broadly the same number of graves, and so they may correspond with consecutive generations (see below). Each sequential generation may have been interred in its own space, adjacent to and slightly overlapping with, or enveloping, the earliest group of burials, which by the end of the sixth century had become a core area, central to this part of the cemetery. Unfortunately, Sewerby remains largely unexcavated and the identification of a small number of burials which do not fit this arrangement, to the east and west of those discussed, implies that this 

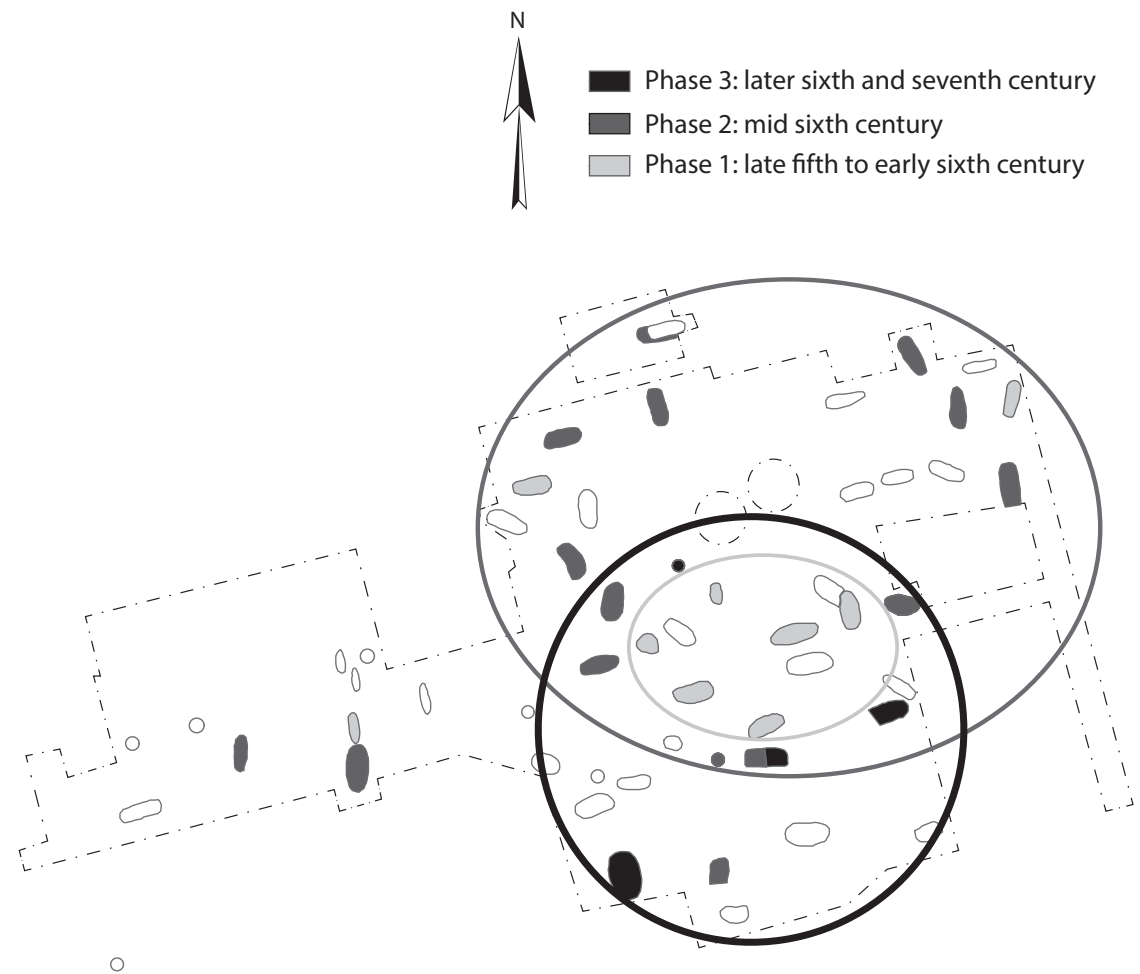

Figure 3.6 Sewerby, highlighting three phases of graves which focused around an earlier core in a concentric organisation.

concentric pattern does not describe the whole cemetery. Perhaps these concentric burials describe just a single plot within the larger cemetery. These occupants were organised by generation, but this pattern might be confined to this plot, becoming an internally distinguishing characteristic that was particular to a group of specific graves, and not a feature of the site as a whole. This organisational feature is something that is discussed in more detail in the description of Dover Buckland below.

As shown in Chapter 2, the early Anglo-Saxon cemetery at Apple Down had different configurations of burial, and these were based loosely on the type of mortuary ritual and the orientation of the grave. Configuration A consisted of inhumation graves oriented W/E and in an interior zone; configuration $\mathrm{B}$ included inhumation graves oriented $\mathrm{S} / \mathrm{N}$ and found in an exterior zone; and configuration $\mathrm{C}$ were cremations found on either side of the central configuration A graves. From a chronological perspective, the cremations and exterior graves are hard to pinpoint because of the absence of diagnostic material culture; 
configuration A burials, on the other hand, included a good number of datable graves and these came from a range of different overlapping dates from the later-fifth to the early seventh centuries (see Table 3.1). The configuration B burials are much harder to date because they contained fewer artefacts, and these artefacts are attributable to much broader dates. However, burials 54, 126, 128 and 145, in the north of the cemetery, had an early to mid-sixth century-character. They were buried with Swanton H2/3 spears or type SP2b1b and SP2a1b2 spears, ${ }^{1}$ type $11.24 \mathrm{~b}(-\mathrm{i})$ buckles, and a button brooch or shield from group 1.1 or SB2-a dated to AD 525-70 (Hines and Bayliss, 2013: 151, 458, 563). By contrast, burials 44, 46, 107, 113, 125, 130, 134, 138 and 151 had a later character and were found with type B2 and B2 b-c beads; knives of types C or D; a Swanton F1/SP1:b spear; pins; and buckles of a general Anglo-Saxon date of the 1.11a-i and 11.19a type (see Figure 1.9 and Figure 3.7). Overall, this pattern implies that the configuration B burials were treated differently. Instead of the vertical pattern presented in the centre of the cemetery among the configuration A burials, the configuration B inhumations had a more horizontal nature and were at least partially buried among groups of contemporaneous graves.

However, there were a couple of graves which complicate this. Grave 12 was of the A configuration, and was interesting because it consisted of two burials: $12 \mathrm{~A}$ was a male burial with a scabbard mount of the SW6-e or Kempston-Mitcham type, placing it in the late-fifth or early sixth century; and then this grave was replaced/destroyed by $12 \mathrm{~B}$, another male buried with a spear, which unfortunately does not fit well into Karen Høilund Nielsen's typology (Hines and Bayliss, 2013) but must postdate 12A. Grave 99 was an exception as, although on a N/S orientation, it had a material assemblage more akin to configuration A. Notably, grave 99 had a spear of the SP3a type and a shield of SB4-b1 with a very small flange width, so probably from the last decades of the sixth century or the early seventh. Perhaps this later date suggests that the central burial system had begun to break down, and the occupants of grave 99 were not eligible for a full configuration A burial.

At Apple Down the different configurations of burials showed a different chronological treatment and importantly this different treatment is also seen among other groups of contemporary graves in early Anglo-Saxon cemeteries. For example, as already seen in Chapter 2, at Wakerley there were three separate plots of graves, and these included a mixture of furnished and unfurnished graves. In the eastern plot $(\mathrm{C})$ there was a core of furnished burials which over successive, repeated burials created a central focus. The remaining two plots were more diffuse having no obvious core of furnished graves. Each of these three areas also contained very distinctive and dissimilar internal chronologies. 


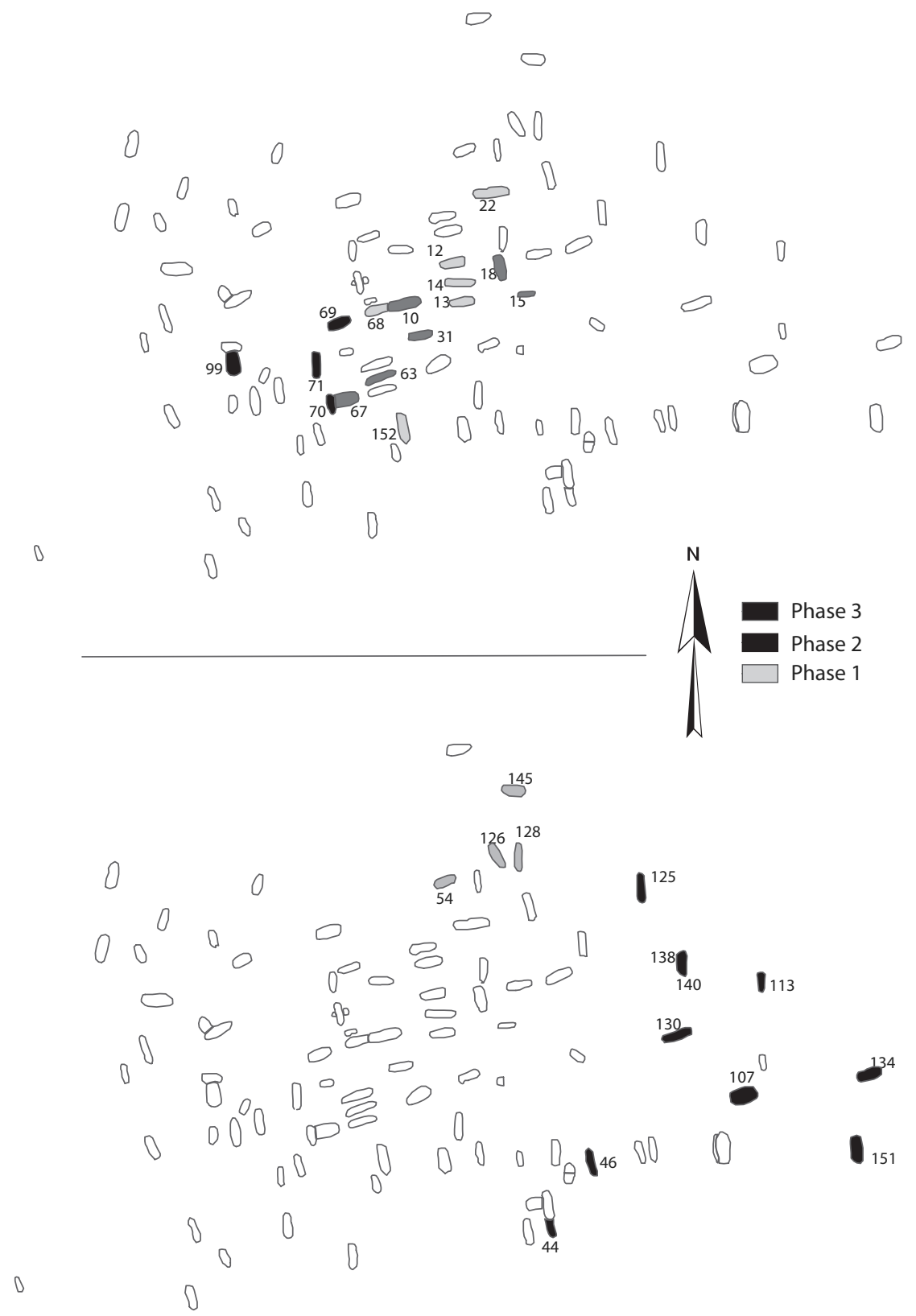

Figure 3.7 Apple Down: the chronology. Top, the core configuration A graves focused on one area that was returned to for generations. Bottom, the configuration B graves showed a more linear pattern with burial 'drifting' to the east of the cemetery. 
Table 3.2 Chronology of configuration A burials at Apple Down

\begin{tabular}{|c|c|c|}
\hline Period & $\begin{array}{l}\text { Grave } \\
\text { no. }\end{array}$ & Gravegoods \\
\hline \multirow{5}{*}{$\begin{array}{l}\text { later-fifth to early } \\
\text { sixth century }\end{array}$} & $12 \mathrm{~A}$ & $\begin{array}{l}\text { scabbard mount of the SW6-e or Kempston-Mitcham } \\
\text { type }\end{array}$ \\
\hline & 13 & saucer brooch 2.1, snake-style ring, two spangles \\
\hline & 22 & knife type B, buckle II.5 \\
\hline & 68 & knife type A, spear H3/SP2-bla4 \\
\hline & 152 & $\begin{array}{l}\text { knife type A, spear of the H1/SP2:b1a2 type, shield } \\
\text { from group } 1.1 / \mathrm{SB} 1-\mathrm{b} \text {, buckle I.11a-I }\end{array}$ \\
\hline \multirow{2}{*}{$\begin{array}{l}\text { early sixth } \\
\text { century }\end{array}$} & 14 & square-headed bow brooch, buckle I.5a, latch lifter \\
\hline & 18 & $\begin{array}{l}\text { bead group A2, two coins, a weaving comb, tube and } \\
\text { purse bar }\end{array}$ \\
\hline \multirow{3}{*}{$\begin{array}{l}\text { early to mid-sixth } \\
\text { century }\end{array}$} & 31 & spear E1/SP2:b1b, I.10a buckle \\
\hline & 63 & $\begin{array}{l}\text { knife B, spear H2/SP2:b1b, small narrow seax/SX1:a, } \\
\text { buckle II.14a, purse bar, tweezers, bucket male } \\
\text { group A }\end{array}$ \\
\hline & 67 & knife type A, spear H3/SP2:b1b, buckle I10a-I \\
\hline \multirow{3}{*}{ mid-sixth century } & 10 & saucer brooch 14.3 , bead group A \\
\hline & 15 & perforated annular brooch group $G$, bucket mounts \\
\hline & 69 & strap end, buckle II.20 \\
\hline \multirow{3}{*}{$\begin{array}{l}\text { late-sixth to early } \\
\text { seventh century }\end{array}$} & 70 & knife type $C$ (cuts grave 67 ) \\
\hline & 71 & knife type D \\
\hline & 99 & spear SP3-a, shield SB4-1b (but E/W orientation) \\
\hline $\begin{array}{l}\text { unknown sixth } \\
\text { century }\end{array}$ & 76 & knife B, buckle I.11a-I \\
\hline
\end{tabular}

In Wakerley plot A, burial 71 was probably the earliest, and was also the most easterly in this area. It contained small-long brooches, B12 wrist clasps and an I.12a-i buckle, giving it a date in the later-fifth century. Grave 70 included small-long brooches, wrist clasps of type B13a and a buckle of type I.7b, all of which associate it with a later-fifth- or early sixth-century date. Graves 73 and 74 both contained beads of group A2 and type $\mathrm{B} 7$ wrist clasps, and grave 74 also contained a cruciform brooch of the Z1 type, suggesting that both graves were from the early sixth century. Burial 78 contained a cognate brooch and burial 80 contained a number of objects, including a great square-headed brooch of type $\mathrm{XV}$, which suggested a mid-sixth-century date as most suitable for these graves. Indeed, graves 82 and 84 both contained annular brooches of 
type IV and group A2 beads. Grave 82 also included a pin set and buckle of type II.19b that may suggest a sixth-century date, so perhaps the beads and artefact combination point to a mid-sixth century date. Similarly, male-grave 83 included a spear of Swanton's E2/SP2-bib variety and shield boss of type 3/SB3-b3, suggesting a mid-sixth-century date. Male-grave 85 contained spears of types H2/SP2-b1a1 and H3/ SP2-b1a3 and a shield of type 1.1/SB1b, which are also objects dating to the mid-sixth century. Overall, these gravegoods suggest that plot A had a general east-to-west horizontal character, starting with easterly burials 70 and 71 in the later-fifth and early sixth centuries. The midsixth-century burials were all to the west, and the latest graves, including grave 79 , were interred in the middle of the plot. Grave 79 seems almost to 'close' the burial space, and, interestingly, this individual was interred with an 'antique' spear, which must have been an heirloom artefact. Metaphorically at least, this spear connected this individual with the past, with the antecedent generations, and its inclusion in this grave may have been a useful way to separate the old and the new (Figure 3.8).

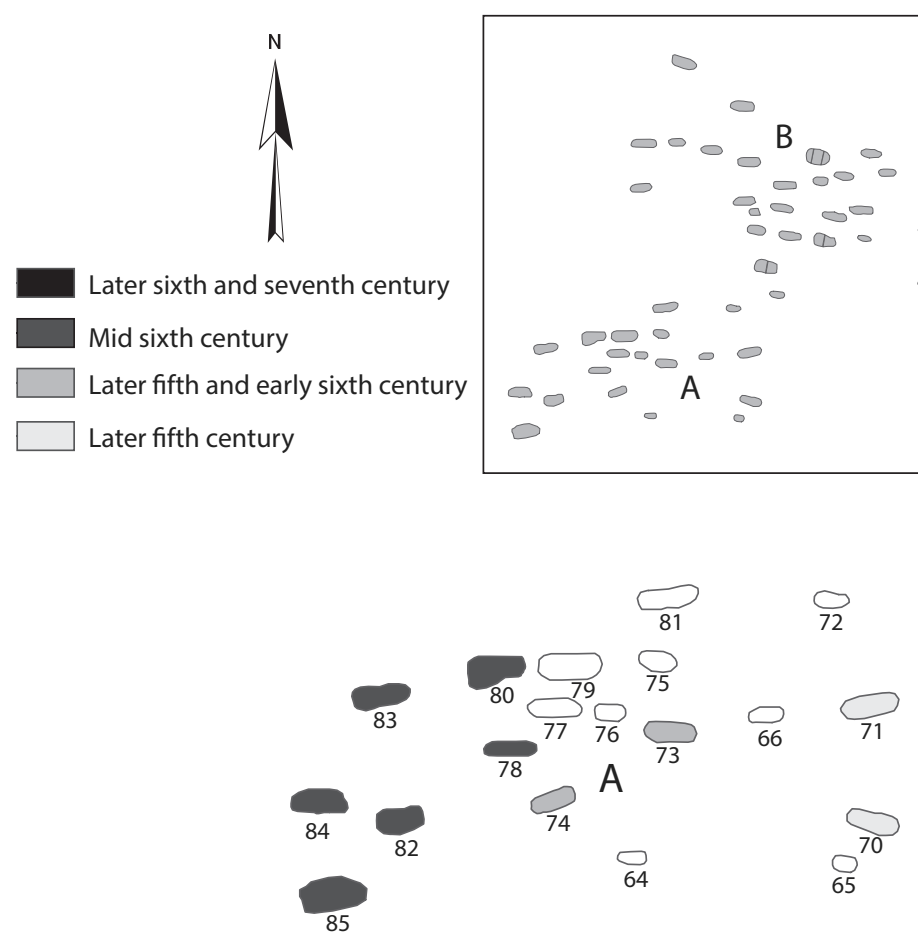

Figure 3.8 Wakerley: plot A had a linear chronological pattern, with burials placed to the west over time. 
Plot $\mathrm{B}$, by contrast, was a concentric plot with the earliest graves in the central area. Graves 4 and 58 appear to have been the earliest; both were found with small-long brooches of a trefoil type, which suggest a later-fifth- or early sixth-century date. To the north of this central area were a group of graves, 3,8 and 57 , most probably early sixth century in date. Grave 3 contained bronze mounts, an F1 spear/SP2-a1a1, a bucket of phase A and an I.12a-i buckle. Grave 8 had applied saucer brooches, and grave 57 included a pin and small-long brooches as well as type B7, B12 and B13c wrist clasps. These five graves, 3, 4, 8, 57 and 58 formed the core area, and on either side were a series of graves which had a different, and so probably later, character. These included graves 1, 61, 62 and 63 to the north-west of the centre. Also, to the east or south-east, were graves 5,10,14, and 69. Grave 1 had a cruciform brooch of type B/C and two of type SB2-s, as well as wrist clasps of type B7. Grave 61 finds comprised type B7 wrist clasps and a buckle of type I.10e. Grave 62 included wrist clasps of type B7 and grave 63 had annular brooches of type IV and a wide-mouthed pot (Myres, 1969: 168). Grave 5 finds were beads of type A2, type B13 wrist clasps, an I.11a-i buckle, a pin, a bronze vessel and a lugged pot. Grave 10 included two type IV annular brooches, a Roman coin and a pin. Grave 14 included a wide-mouthed pot which, although hard to date, Myres attributed by its appearance to the latter half of the sixth century. Grave 69 included B7 wrist clasps and a belt buckle of the I.11a-I type. Individually, these artefacts in grave 69 are datable broadly to the sixth century, but within this grave plot, and buried together, they are an assemblage which is of a very a different style to the previous burials, and probably dates to the middleto later-sixth century. Inhumation 17 is the only one which was more obviously of the later-sixth century, it contained two type IV annular brooches, a penannular brooch, a silver bracteate, a scutiform pendant, type B7 wrist clasps, two II.21b buckles, as well as a girdle-hanger, a comb, keys and a pin (Figure 3.9). Overall, this area of the cemetery had a similar range of date to the plot $\mathrm{A}$, with just a single, later grave marking its end.

The third area, plot C, contained seven of the ten double burials excavated, and this corresponded with a greater density in inhumations. None of these graves included evidence of reopening or of the second burial being added later, and so the two corpses were in all likelihood positioned in the grave at the same time. The earliest burial is probably grave(s) 31/32, where 31 had a small-long brooch, an A2b bead combination and a gilt/iron style I animal art mount. Grave 32 had an annular brooch fragment, a small-long brooch and a cruciform brooch of type $\mathrm{D}$, a combination that implies an early sixth-century date. Double grave $42 / 43$ was also early sixth century, where 42 had applied brooches, a 

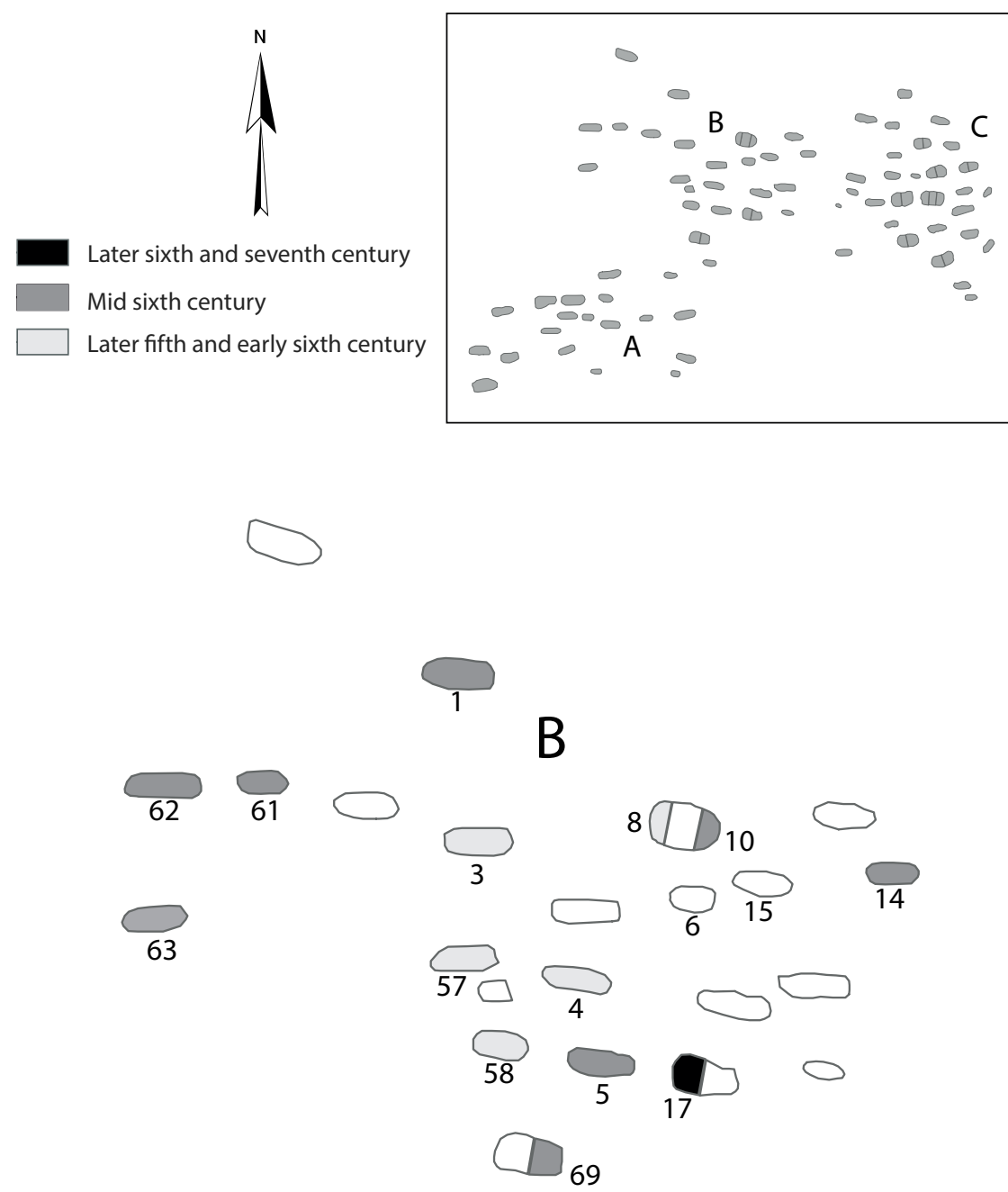

Figure 3.9 Wakerley: plot B had the early burials in a more concentric pattern, with earlier burials in the middle.

cruciform-type $\mathrm{Z} 3$ brooch, two silver ring pendants and a wire spiral wrist clasp of class A; however, no gravegoods were identified from grave 43. Graves 25/26 were found with cruciform brooches of type SB2 and B7 wrist clasps, suggesting a date in the first half of the sixth century. Chronologically, grave $22 / 23$ straddled the early to mid-sixth century and contained an E3 spear/SP2-a, a type 3/SB1-b shield boss and a type1.1SB3-b2 shield boss, but most likely dated between AD 525 
and 570. Given grave 23's later character, perhaps it fitted towards the end of this date range.

Similarly, grave(s) 50/51 also straddled the early to mid-sixth century. Grave 50 contained annular brooches, a great square-headed XV brooch, wrist clasps of $\mathrm{B} 7$ and $\mathrm{B} 13 \mathrm{c}$ types, a string of $\mathrm{A} 2$ beads and a II.21a buckle, all of which place it in the middle decades of the sixth century. However, grave 51's L-type spear, and shield boss of type 1/ SB1-b, might suggest an earlier date. The individual in grave 51 was an older man, and so perhaps the shield boss was old-fashioned when it was buried in or around the beginning of the middle-sixth century. Double grave 44/45 contained two women, and both sets of gravegoods tend towards the middle decades of the sixth century: grave 44 contained cognate brooches, an imported square-headed brooch, A2 beads, a Roman coin, a girdle-hanger and keys; grave 45 included small-long brooches, B13c wrist clasps, A2 beads and a type II.21b buckle. Finds from triple grave 52/53/54 also suggested a mid-sixth-century character. Grave 52 contained spears of H1, L and F1 forms (or types SP1-b, SP2-bib and SP5), grave 53 included an I.11b buckle, and grave 54 a pin and a ceramic vessel. The only later grave associated with plot $\mathrm{C}$ is burial 21, which had a type VII penannular brooch, B7 wrist clasps and a II.19b buckle. Other graves with a single individual within them dated to the early and mid-sixth centuries. Like the central burial area at Apple Down, this plot had a vertical chronological pattern, with successive burials placed adjacent to each other in a high-density area of the cemetery (Figure 3.10). Just as at Apple Down, these graves contained larger amounts of material culture relative to the rest of the cemetery. This depositional pattern took place across a series of generations, who each returned to the same central space within the cemetery to bury their dead.

Oakington, Cambridgeshire, had a rather different pattern. This early Anglo-Saxon cemetery was first identified in 1926 when three burials were found (Meaney, 1964). Subsequently, in 1994, a further twenty-six burials were excavated (Taylor et al., 1997) and in 2007 a further seventeen burials were excavated before construction of the parish recreational building (Mortimer et al., 2017). A further seventy-eight burials were excavated between 2010 and 2014 as part of a university research programme, taking the known cemetery total to 124 individuals. It is speculated that this is over 80 per cent of the total original extent of the site (Mortimer et al., 2017). Radiocarbon dates from Oakington help us to understand its chronological development. There are eight radiocarbon dates that point to a later fifth- and sixth-century range (see, for example, Schiffels et al., 2016; Mortimer et al., 2017). Based on material culture the site is understood as similar to Wakerley in that 

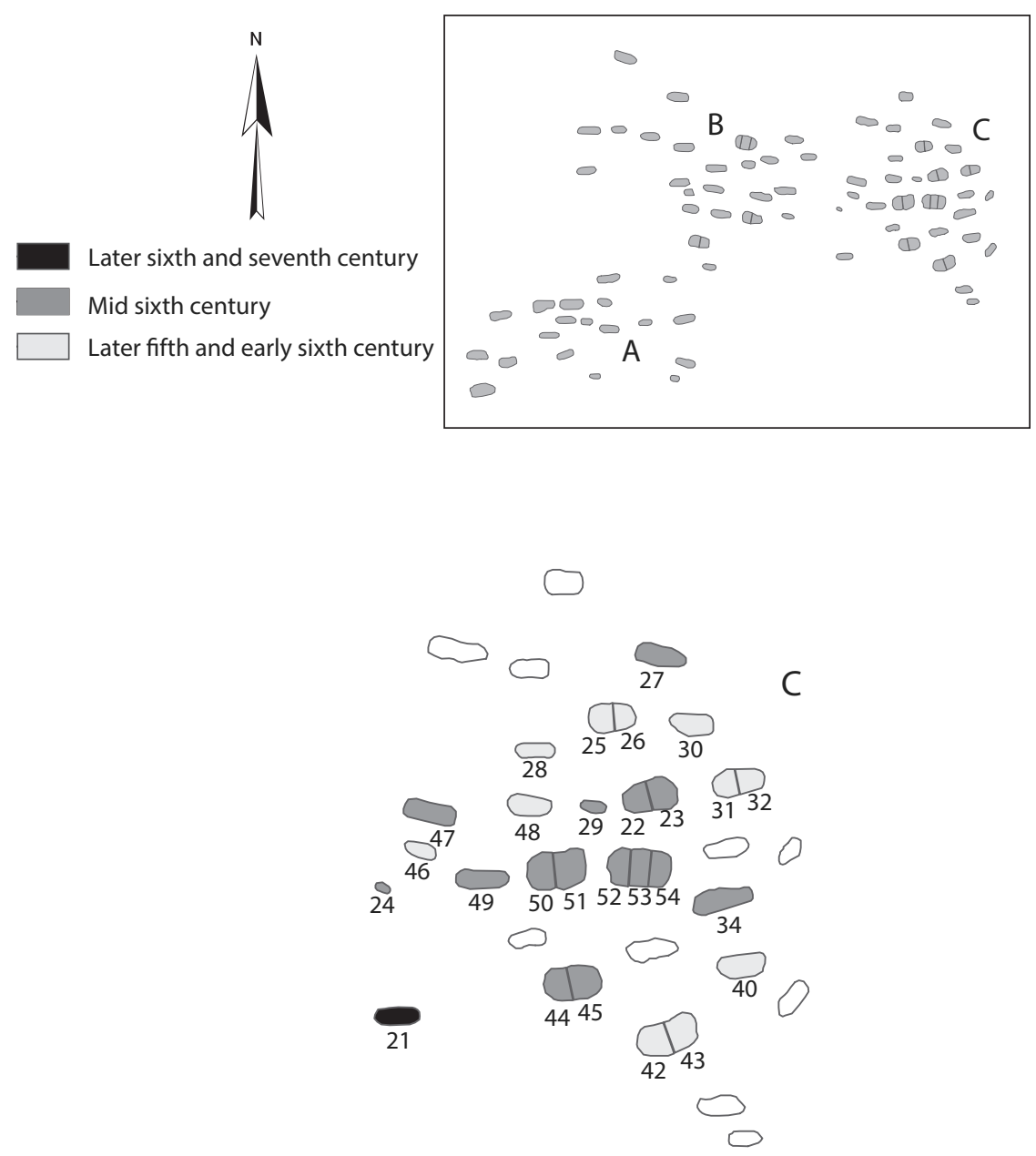

Figure 3.10 Wakerley: plot C consisted of densely packed multiple graves.

Generation after generation returned to this area, which showed limited horizontal patterning as a result.

it was in use for about one hundred years between the later-fifth and later-sixth centuries (Figure 3.11).

Interestingly Oakington seems to have been organised around a series of key burials. For example, Burial 57, a pregnant woman, was interred in the later-fifth or early sixth century (also see Sayer and Dickinson, 2013). Her cruciform brooch was a typical example of type 3.3.1, belonging to cruciform brooch phase $\mathrm{B}$ and dating between c. AD 475 and c. AD 550, corroborated by radiocarbon dates. She was also found with two trefoil small-long brooches, a string of beads, 
OxCal v4.2.2 Bronk Ramsey (2013); r:5 Atmospheric data from Reimer et al (2009);

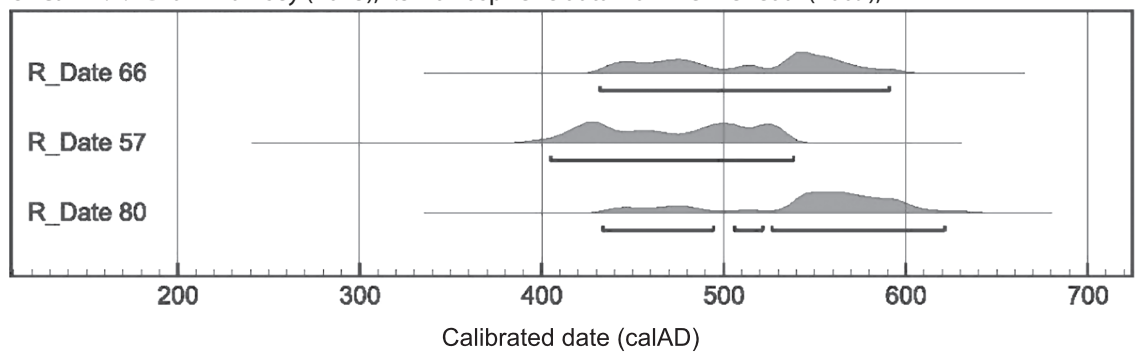

OxCal v4.2.2 Bronk Ramsey (2013); r:5 Atmospheric data from Reimer et al (2009);

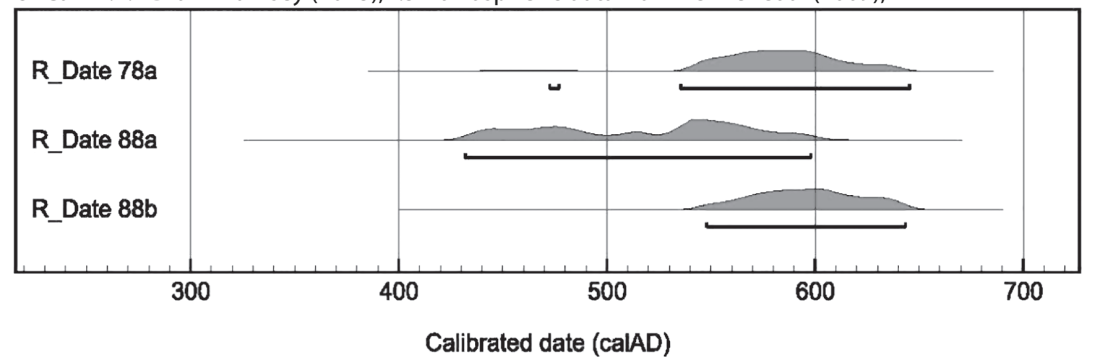

OxCal v4.2.2 Bronk Ramsey (2013); r:5 Atmospheric data from Reimer et al (2009);

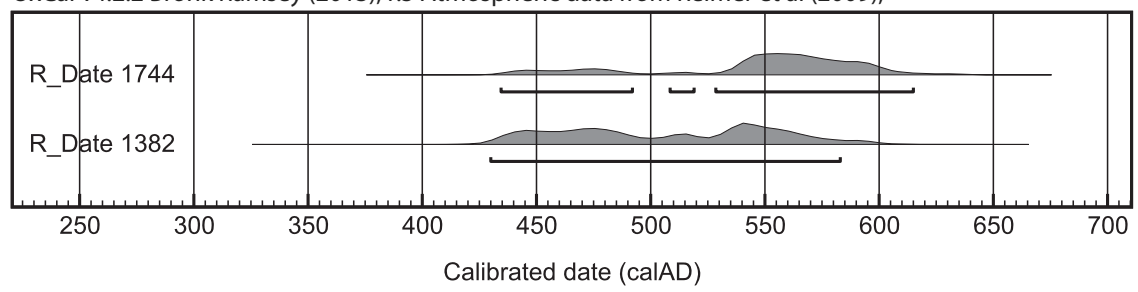

Figure 3.11 Oakington: calibrated radiocarbon dates for graves 66, 57, 80, 78a, $88 \mathrm{a}$ and $88 \mathrm{~b}$, as well as for horse burials 1744 and 1382 .

two wrist clasps, an iron purse ring, copper-alloy belt fittings and an iron knife. Unfortunately, at the time of writing grave 109 does not have radiocarbon dates, but gravegoods including two applied saucer brooches imply a late-fifth- or early sixth-century date. In addition the grave included wrist clasps, a knife, a purse ring and a metal hinge, which may have been part of a box, and over forty amber beads. The child was found with a single copper-alloy ring resting on the chest area below the chin.

The female in grave 66 was found with a whole pot, keys, wrist clasps, a number of amber beads and two pierced copper-alloy pendants. She was also buried with two trefoil small-long brooches, found on her 
chest. She had wrist clasps of types B13b and B18c, a copper-alloy pin and an iron key or latch-lifter belt-hanging set, adjacent to which was hung a Roman spoon. In addition, her grave included a pottery fragment at her feet. The radiocarbon dates are less precise than for grave 57, but the burial was similar in character and so she was probably buried in the early/mid-sixth century. The occupant of grave 80 was buried with an almost complete cow. She also had forty-six amber beads and twenty-two glass beads. The beads were in at least two strings, one of which was draped over her arm and the other close to her body. She had two small, silvered disc brooches, two B7 wrist clasps and an iron girdle-hanger. Based on these objects and the radiocarbon dates, it is probable that this grave was created in the mid-sixth century. Curiously, four of the five prone burials excavated at Oakington were adjacent to this grave, and one of these was datable. Grave 78 was a double burial containing a prone adult female and a child, and it was dated to the mid-sixth century (see Chapter 1), a date supported by the radiocarbon results. She was found with seventeen beads, wrist clasps, a small-long brooch, an iron knife and a meat bone. Her burial was found in a satellite position around grave 80 , indicating that burial 78 postdated it.

The dates for burials $88 \mathrm{a}$ and $88 \mathrm{~b}$ overlapped and suggested they were part of the final phases of the site; perhaps they had been interred in the period AD 550-75, in the latter half of the mid-sixth century. The associated gravegoods included a shield boss (of the Dickinson and Härke group 1), a Marzinzik 11.19a buckle as well as a copper fitting from the shield, but unfortunately it is not possible to ascertain a further type at this stage.

All of these graves, with the exception of 78 , are included here because they appear to have significant space and/or satellite burials around them. Indeed, 57, 80 and 88 were associated with a large mammal burial, either a horse or a cow. As with Lechlade, Finglesham and St Peters for example, these spaces were consistent with the location of small barrows, unfortunately no longer extant, which marked the burial. Graves 57, 66, 80 and 88 had satellite burials associated with them. Satellite graves are later graves which deliberately snaked around or were partially inserted into the barrow along one of its edges (Figure 3.12). These barrows created central places, and the subsequent burials show that they were returned to repeatedly after their creation. The discussion of artefacts and radiocarbon dates above suggests that these burials were deposited in sequence, probably starting with inhumation 57 in the late-fifth or early sixth century. This was followed by grave 66 in the early sixth century, then grave 80 in the middle-sixth century and grave 78 in the later-middle-sixth century. In short, these small-barrow burials were created roughly every generation. There was 


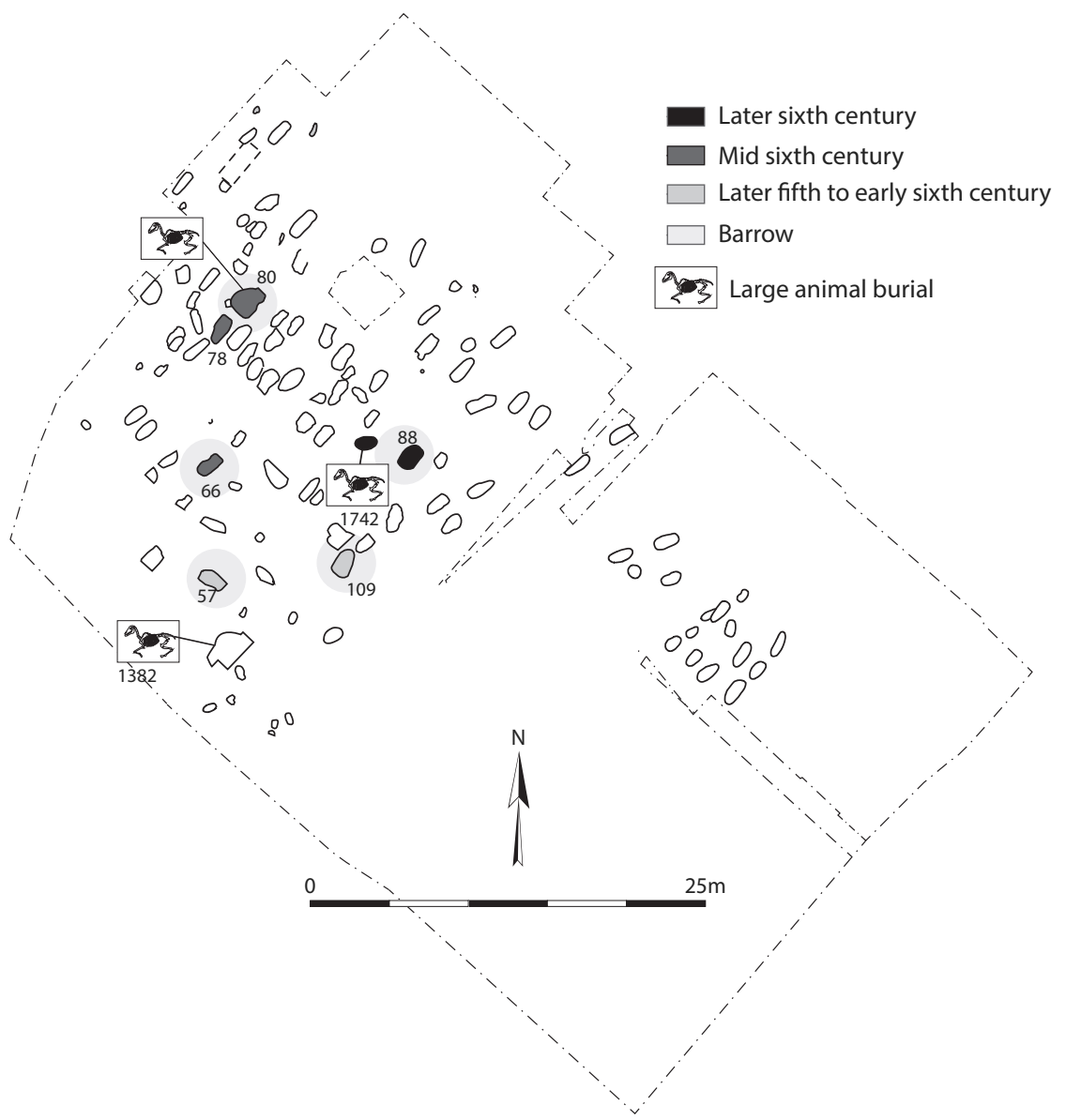

Figure 3.12 Oakington barrows: these burials were significant central points, but the focus seems to have shifted to a different barrow in each subsequent generation.

not a single central place where burials were returned to at Oakington, but instead the graves of individuals became short-lived central places that attracted later burials, often from the same generation. This is an ego-centred burial organisation because this scenario means that the community who used and returned to the cemetery space hung narratives upon, and told or retold stories about the individuals under these mounds, and they even placed the newly dead adjacent to particular mounds, highlighting a specific relationship. It looks as though each generation had a significant individual whose burial created a focal point for subsequent graves. Notably at this site these inhumations were mostly female graves, which may say quite a lot about the nature of 
this specific community (see chapters 4 and 5 for a further discussion of gender).

\section{Dating Dover Buckland}

We introduced the early Anglo-Saxon cemetery at Dover Buckland in chapters 1 and 2. The site was first excavated in 1951 and again in 1994. Together the two excavated elements included about 507 graves. Dover Buckland has been very influential in the development of Kentish, and indeed national, early Anglo-Saxon chronologies. As a result it makes sense to substantially revisit this site in this chapter. The 1951 project was the first long-lived Kentish cemetery excavation to be have been published since the nineteenth century, and so made an important contribution to chronology studies (Brugmann, 2012). In particular, the excavation developed its typology using absolute dates based on coins in graves and developed a chronological scheme of its own, one that influenced the dating of garnet brooches, shield bosses, swords and, in particular, knives (Evison, 1987: 21-121). This scheme received minor adjustments from Brugmann in her assessment of the later excavation because it showed a tendency to date graves too late, compared with earlier dates provided by subsequent radiocarbon dating. Nonetheless, the chronological phases established by Evison were left intact 'for ease of reference' or for comparison with the previously published volume, and further information could be used to subdivide date ranges providing better chronological resolution for some graves (Brugmann, 2012: 323). After these overlapping approaches were published, the Hines and Bayliss chronology project was completed. This project adds additional resolution, in particular for male-gendered graves, and this provides the starting point from which to revisit the dating of Dover Buckland and explore the organisation of the cemetery space. The dating scheme described in this chapter has been applied to Dover Buckland, and particular attention has been paid to the way Hines and Bayliss' chronology project impacts the male chronology. Appendix 1 lists each grave described here, and whether or not the dates in the two different schemes correspond.

Vera Evison used her chronological system to suggest that there was a single organising principle, an east-to-west burial direction (see Figure 1.3). To some degree this observation holds up with the new chronologies, but it does presuppose that there was a single architect, or narrative, which remained intact for the history of the site. Dover Buckland is a notably complex site and, like the other cemeteries discussed here, it had numerous architects with different and changing ideas about burial practice. This can be seen in the multiple chronological patterns which 
were in use at the same time. These individual parts are familiar because the same principles can be seen in the other cemeteries discussed in this chapter, and throughout this book.

The 1951 site is the northern part of the cemetery, and its earliest phase is to the west, described by Evison as plot A. However, area L also contained a single late-fifth/early sixth-century burial, grave D; otherwise it contained graves which dated between the later-fifth and mid-seventh centuries (Figure 3.13). Area L was dispersed and appears to have had no particular chronological character (Figure 3.14), and in this way it was similar to the westerly plot at Wakerley, Northamptonshire, if somewhat smaller. Graves 15 and 20 were the earliest datable graves. To the north of them, burial 87 was dated between the fifth and mid-sixth century, whereas graves 22, 48 and 92 contained mid-sixth-century objects (see
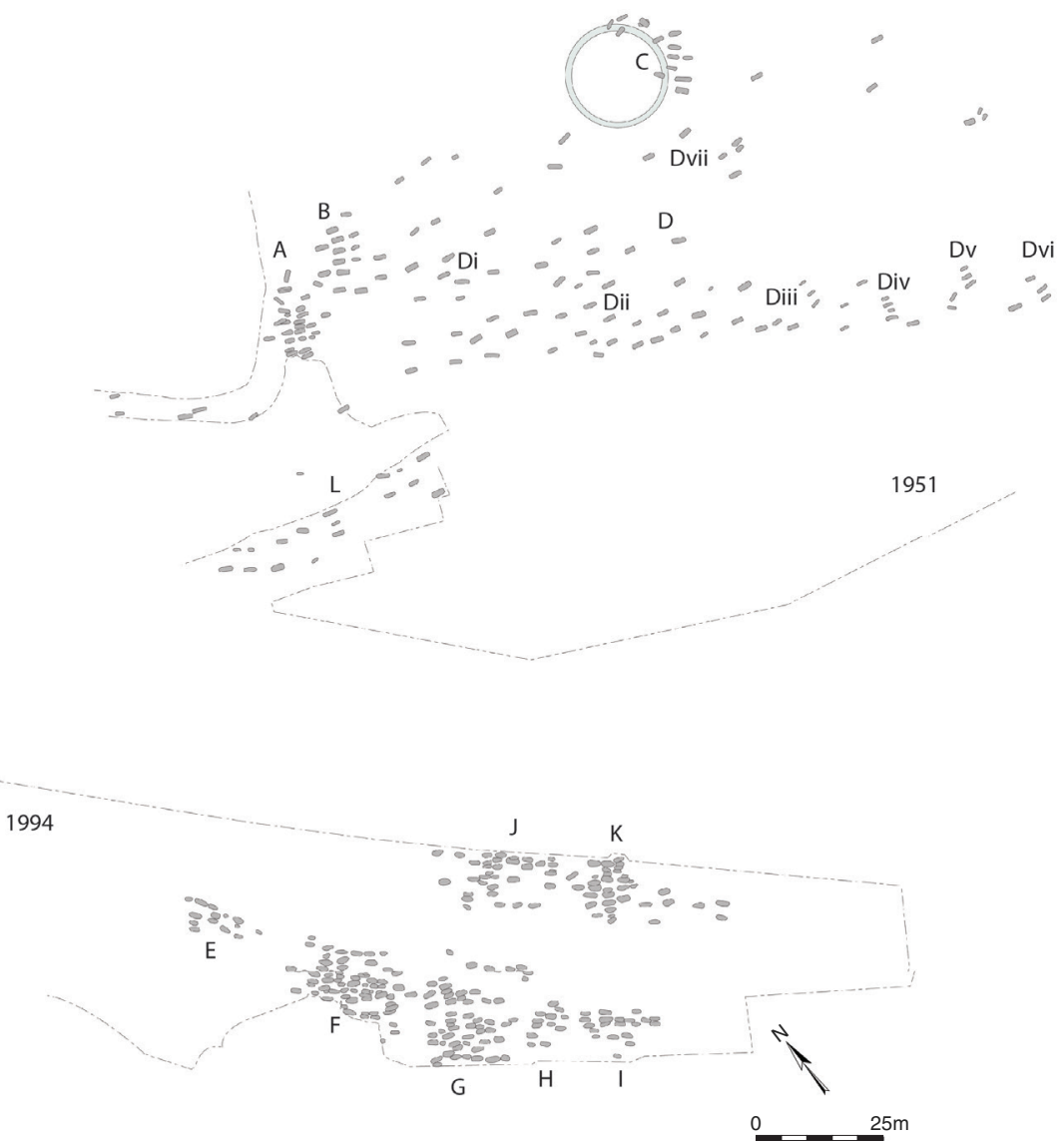

Figure 3.13 The 1951 and 1994 excavations at Dover Buckland, with the burial plots labelled. 


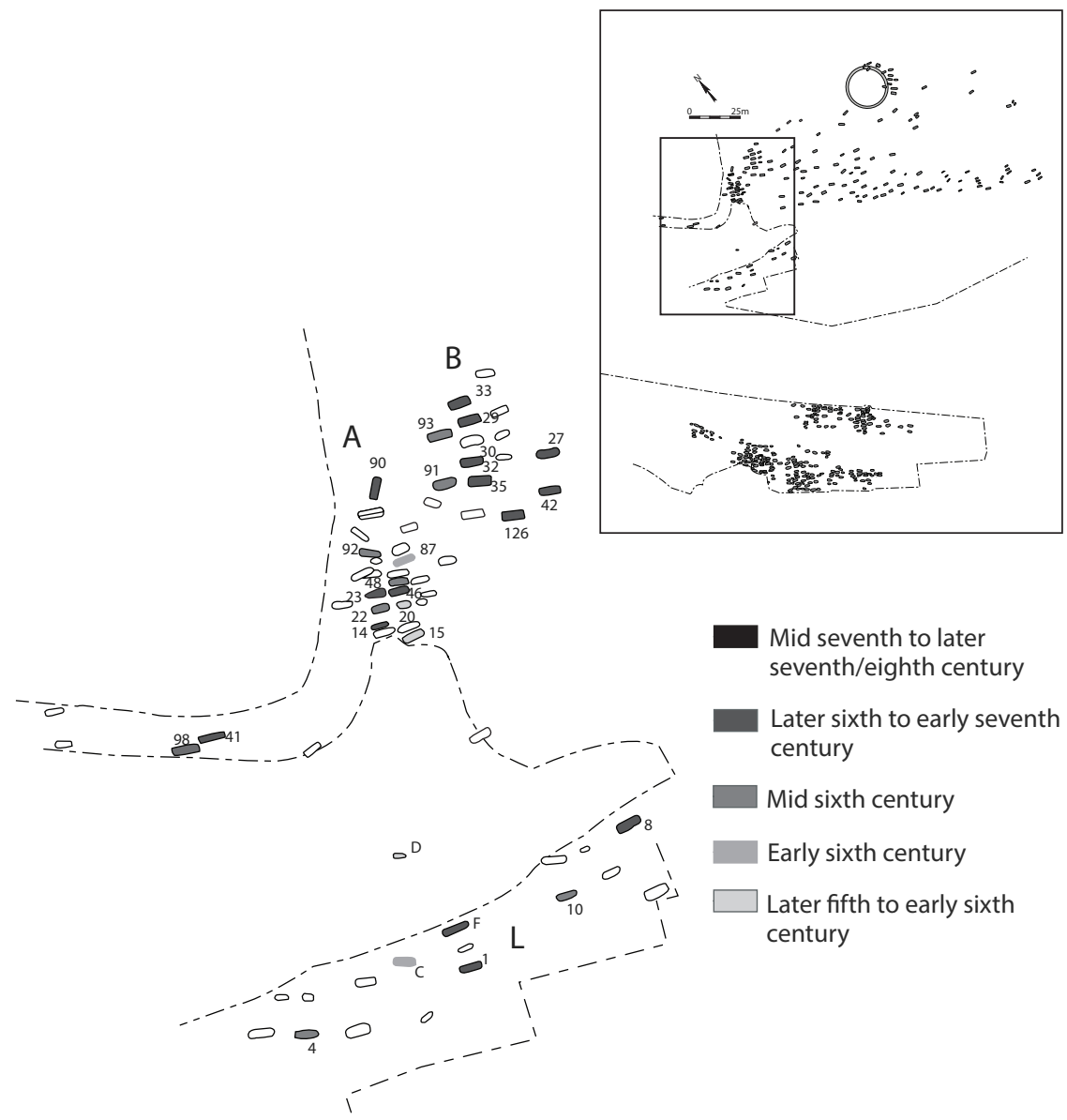

Figure 3.14 Dover Buckland: plots A, B and L in the 1951 excavation area. Plot A was an area of dense burial returned to repeatedly throughout the fifth and sixth centuries. Plot B, however, consisted primarily of a line of contemporary burials interred in the later-sixth century, as at Deal. Plot L contains some of the early burials and was among the first areas excavated, but large parts either remain unexcavated or have been lost.

Appendix 1). Most reminiscent of Wakerley, the later-sixth- and early seventh-century burials 14, 46, 23 and 90 were dispersed between, and placed around, these graves. At the same time, to the east, in an area described by Evison as plot B, burials 91 and 93 were placed in the middle-sixth century. In contrast the graves within plot A were densely packed, crowded into a particular space and were returned to for two or three generations. However, this burial style was short-lived, and to the east of burials 91 and 93 there was a row of broadly contemporary 


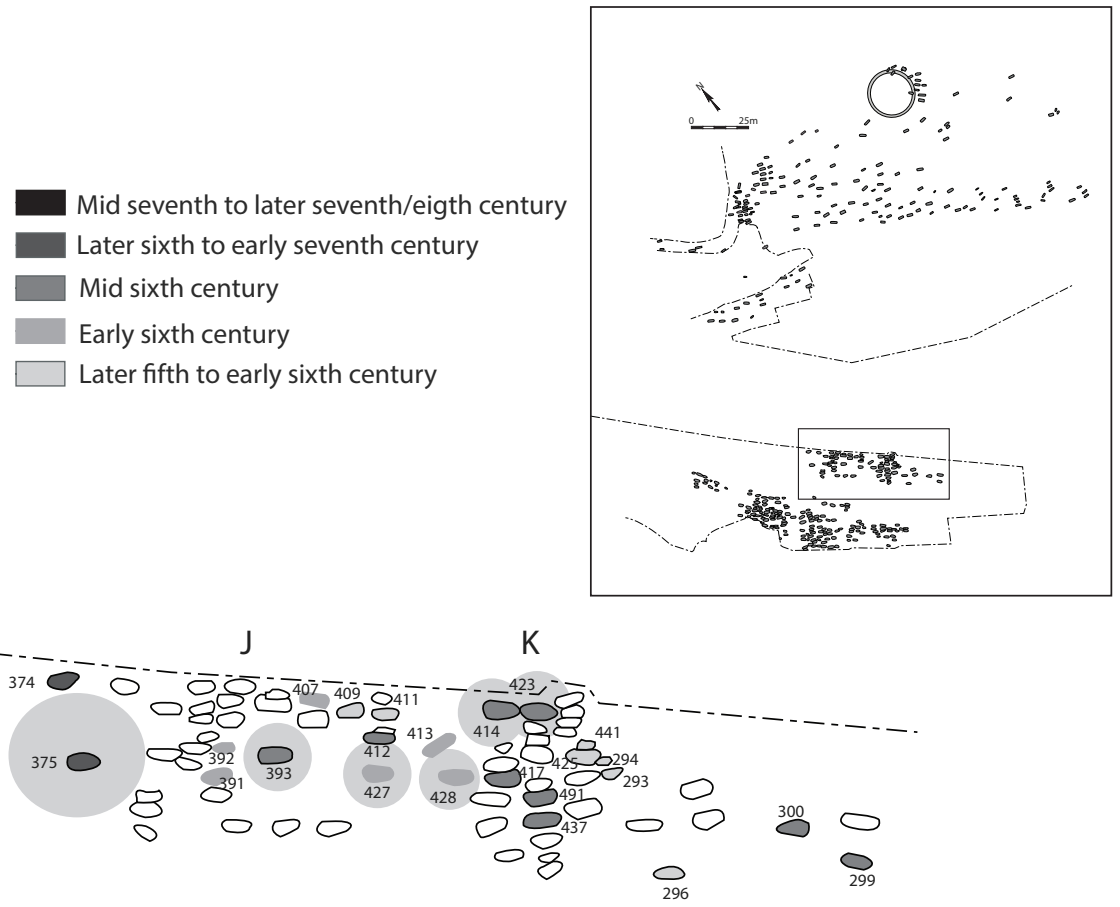

Figure 3.15 Dover Buckland: plots J and K in the 1994 excavation area. This was actually a single plot which had a pair of significant burials placed in each generation, then surrounded by satellite graves, as at Oakington.

graves, mostly dating to the later-sixth and early seventh centuries. This is strikingly similar to Mill Hill, Deal, where, as we have seen, a row of later-sixth and early seventh-century graves was placed next to the sixth-century plots (Figure 1.5). The mourners at Deal and in this part of Dover Buckland were changing the space and style of the burial, adapting the aesthetic of the mortuary landscape to suit a new idea, or a new way to identify their dead.

Interestingly, the 1994 excavated part of the cemetery had a similar origin. There were seven plots; E, F, G, H, I, J and K. The most striking of these was J-K, which was probably just one large plot (Figure 3.15). This is one plot because the 'gap' perceptible in plan was filled with several small barrows that joined it together, in a similar way to those we have also seen at Deal, Lechlade and Oakington (in this chapter; also see Chapter 4). Graves 393 and 427, in J-K, had ring gullies around them, providing direct evidence of these barrows. Grave 428 did not have a ring gully, but instead graves 413, 416, 417 and 429 enveloped it. Keith Parfitt and Ian Anderson (2012) proposed that burial 413 was originally beneath a barrow because it had a small amount of room 
around it. Notably this grave was on a different orientation to those adjacent to it, and graves 416, 417 and, in particular, 429 leave the shape of the barrow that they surrounded like a negative feature. Grave 428 was female-gendered, and contained two gilt saucer brooches, a buckle, beads and a perforated Roman nummus. Similarly, to the east of these graves was burial 423, a weapon burial. Enveloping this grave were burials 424, 442, 443 and 444, which seem to have been oriented to it, and, as we saw before, these graves 'dog-leg' around a circular or semi-circular space, where a barrow had been placed, and traced around its edges. Grave 422 marked the southern edge of this space. Grave 414, to the west of 423, was another weapon grave, with spear, shield and sword. These last objects were datable, and placed grave 414 in the mid-sixth century, a similar date to its pair, grave 423 . The location of grave 414, the placement of grave 415 in a satellite position and the space around it suggested that both 414 and 423 had barrows over them. These two graves were dated at AD 525-95 for grave 414, and AD 525-50 for grave 423, which certainly allows them to be broadly contemporaneous.

To the south of these two barrows, inhumation 437 was another weapon burial. It contained a sword and, unusually, a hooked iron atgeir, a halberd-like weapon that the excavators described as a 'fauchard', which is a type of polearm weapon more common in the Middle Ages (Parfitt and Anderson, 2012: 450). This weapon is certainly extremely unusual if not unique within the mortuary record, and as a result it would have singled out its user and was probably associated with them in life (Sayer et al., 2019). The space between this grave and graves 419, 434, 436 and 438 also implied that originally it was beneath a small barrow. The final barrow was associated with grave 375 , which included a spear, sword and shield. This barrow was larger and later, and later graves 371, 374, 376, 385, 386 and 388 enveloped it, preserving the barrow's edges with their orientation. With these barrows located as described there would have been no significant gap between plots J and K, which should therefore be seen as a single large plot.

The chronology of plot J-K is notable and perhaps most resembles the description of Oakington, discussed above. Graves 293, 294, 425 and 441 were sparsely furnished female-gendered graves situated to the east, and were also among the earliest graves. Inhumation 294 contained group A beads (AD 450-80), burials 425 and 441 contained A2 beads (AD 450-530), and grave 239 contained A1 beads, dated AD 450-570. The different styles of these beads suggest that they were not contemporary, but these four burials seem to have been closely placed, so they were consecutive burials with stylistic similarities. They were probably interred in close succession in the later-fifth or early sixth centuries, 
and all were probably young adults or children, buried together by the adults that survived them, in a new cemetery space. In close association with these children's burials was inhumation 426, an adult female, aged 40-50, unfortunately not datable.

In the middle of plot $\mathrm{J}-\mathrm{K}$ were two datable graves, 409 with A2 beads (AD 480-555), and 411 with a spear dated $A D$ 450-525, dates which place these two graves among the earliest in the cemetery. The two barrow burials to the south, 427 and 428 , were dated to the early part of the sixth century. Grave 427 was interred with A2 beads, like the other early female-gendered graves. Grave 428 was also interred with A2 beads and, as previously mentioned, two small gilt saucer brooches suggesting an early/mid-sixth-century date. As with the Orpington barrow burial (Chapter 1), these two examples were not richly furnished.

Clockwise from burials 427 and 428 were the double barrows 414 and 423, which have already been introduced as mid-sixth-century inhumations (see above). Grave 414 contained a type SP1-b spear and SB3-c shield boss with a combined date range of AD 525-95. Grave 423 continued a SP2-b1a3 spear dated AD 525-70. It therefore makes sense to suggest that grave 423 was the earlier of the two, especially given that the later satellite burials skirt around it, but have no direct relationship with 414. South of these two burials was grave 437 , attributed by Brugmann to phase 2 and dating from AD 510/30-550/60 or the early/ middle sixth century (Brugmann, 2012: 323). Its satellite burial 417 was probably interred later, and was a female-gendered grave with type-A beads, a great square-headed brooch, a radiate-headed brooch and a crystal ball, among other objects, which firmly dated it to the mid-sixth century, perhaps (as Brugmann suggests) the first part, placing both burials close to, but before, AD 550. Both graves were of adults, whereas the graves immediately to the north and all three southern burials contained adolescents.

Grave 393 had a similar date, and a spear of SP2-b1b suggests a date of AD 525-70. This male-gendered grave had a number of satellite burials, the two that were datable being burial 392, with a buckle (undatable) and A2 beads, and burial 391, which included A2 beads and a great square-headed brooch, placing it firmly in the middle of the sixth century. Also to the west of the plot was the latest barrow burial, grave 375, with spear of type SP3a and a shield of type SD4-b2 dated AD 525-645, for which Brugmann's phases within the $3 \mathrm{~b}$ category suggest a date more like AD 580-645 (Brugmann, 2012: 323). Satellite burial 376 contained B2 beads, which dated it to AD 580-650, and twisted iron keys, which might imply that this burial was more sixth-century in date. The grave's location on the western edge of the plot, and its coherence with the 
location and material style of the other sixth-century graves, suggest that it had a later-sixth-century date. This burial and a few of its satellite graves marked the end of this sixth-century tradition in plot J-K.

Plot $\mathrm{J}-\mathrm{K}$ is also very similar to Oakington in that it was organised around the burial of a number of significant individuals, highlighting an egocentric commemorative practice, with satellite burials placed around small pre-existing barrows. Plot J-K highlighted key members of the community, and it looks as if there were one or two of these individuals from each generation. These burials were returned to for a number of years; the positioning of subsequent satellite graves, and the digging and visiting of them would have allowed the community to remember not only the recent dead, but also the key ancestor buried beneath the associated adjacent small barrow.

Plot E was small and consisted of just fourteen graves (Figure 3.16). The datable ones included burials 204 and 207, which had the narrowest possible range. Grave 204 was dated probably AD 530-60, based on a garnet disc brooch and gold bracteate, while grave 207 dated to AD 450-580 based on associated bead finds. Overall, this area was characterised by a smaller number of finds. Burials 205 and 209 were placed into phases 2-3 (AD 530-80/600) and 1b-2 (c. AD 480-580/600), and together these four burials implied that this was a short-lived group that was in use for a generation or two.

Plot $\mathrm{F}$ was more substantial than plot $\mathrm{E}$, and the associated artefacts suggested a wider range of dates that might imply that the artefacts were used between the later-fifth- and the early seventh centuries; however, this plot largely had a sixth-century character (Figure 3.16). The focus of the plot gradually shifted away from the earliest graves, which were later sidelined towards the edges of the plot. Graves 217 and 218 were the northernmost, and both were buried with A1 beads, although interestingly no other items of jewellery. Inhumation 398, to the east of them, had a broad chronological range, and was phased by Brugmann in 2b-3a ( $\mathrm{AD} 530-80$ ), which placed it in the middle-sixth century and therefore followed on from 217 and 218. Together, these three graves might imply that the group of graves to the north of plot $\mathrm{F}$ had a broadly linear chronological nature, starting in the east in the later-fifth century and ending in the middle-sixth century to the west. Unfortunately, graves 273 and 397 were not datable.

The southern part of plot $\mathrm{F}$ was interesting because it contained the most intercutting of any area within the Dover Buckland cemetery, and consequently it boasted the densest concentration of graves. This illustrates the degree of earlier burial, with a number of undated or unfurnished graves that had early dates because they were intersected by later graves. Inhumations 212, 229, 232, 235, 261, 263, 320, 347, 349, 
Mid seventh to later seventh/eight century

Later sixth to early seventh century

Mid sixth century

Early sixth century

Later fifth to early sixth century

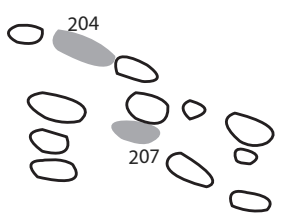

$\mathrm{E}$

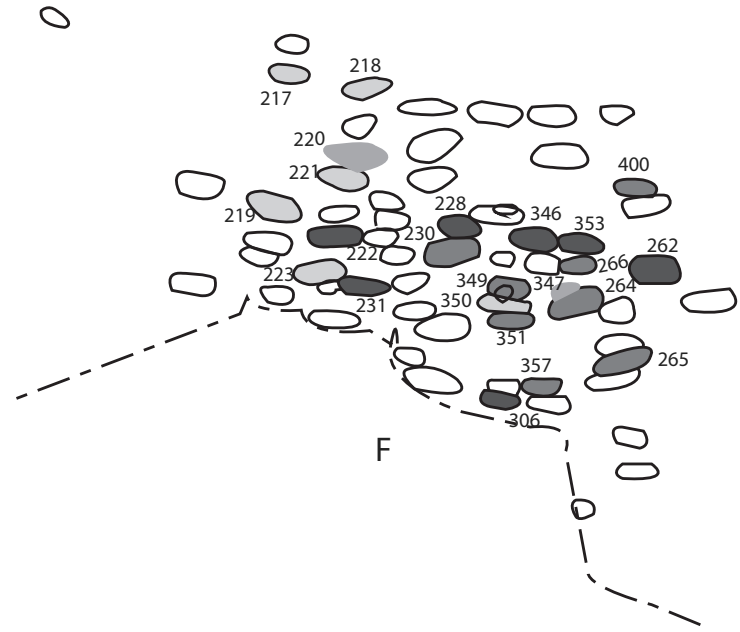

Figure 3.16 Dover Buckland: plots E and F in the 1994 excavation area. Plot F had a line of contemporary later graves which ran through the centre of the area. It may have had a loosely arranged linear organisation, with burials placed to the south-east.

351 and 352 were examples of graves cut by later ones. Burial 261 is of phase 1 because it was cut by grave 266, which was a grave dated to the first half of the sixth century, and female-gendered because it contained two silver radiate-headed brooches. Grave 347 was datable to the first half of the sixth century because it contained A2 beads, a glass cone beaker, a small square-headed brooch, a radiate brooch, and an openwork brooch, and was cut by burial 264 , a mid-sixth-century grave.

The most obviously mid-sixth-century graves were placed across the centre of this densely populated area and included graves 230, 264 and 
349. Grave 230 contained a SP2b1a3 spearhead and a SB1B shield boss, placing it between AD 525 and 570. Grave 264 had the same dates, and contained a SP1b spear and a SB3B3 shield boss. Grave 349 contained a SP2b1b spearhead, which Brugmann placed into phases 2-3, and probably dated AD 510-70. Notably, grave 265 to the south was also midsixth century (AD 525-70), with an SP2b1a2 spearhead and an SB3a shield. What is particularly interesting about these contemporaraneous graves is that they were all male-gendered weapon burials, placed to intercut with earlier graves in the centre of the plot, and so it was this mid-sixth-century phase that saw the density of burial in plot $\mathrm{F}$ becoming its defining feature. Notably, however, intercutting is not limited to male graves, since grave 354 was female-gendered and cut both 269 and 361 , as did the later-sixth-century grave 360 . Grave 354 contained A2b beads, and grave 360 had B2 beads of a different character, and so these individuals were probably from different generations.

There were a few later-sixth- and early seventh-century graves in plot F which appear to trace the middle of the plot. Grave 262, on the southern edge of the plot, was the earliest of these. It contained a SP1a1be spearhead giving it a depositional date range between the midsixth and early seventh centuries. This means that this grave could have belonged to either the group of mid-sixth-century intercutting graves, or to a similar group of later-sixth- or seventh-century graves. Its position on the edge of the plot, and in line with 346 and 353, tends to suggest the latter, placing it in the second half of the sixth century (see Figure 3.16). Grave 353 cut 352, partially obliterating it. Grave 346 was a weapon burial which contained a sword and a SP2-a2d spearhead, dating it AD 585-680. Grave 353's B2 beads dated it to AD 580-650, as did a garnet disc brooch with Salin Style II animal art. Grave 228 was further west than 353 and 352, and cut burial 231 which Brugmann placed in phase $3 \mathrm{~b}$, meaning that 228 must have dated to the later portion of the sixth or early seventh centuries. Graves 222 and 231 were to the western side of the plot. Grave 222 was dated with B2 beads between AD 580-650, and 231 contained an impressive decorated buckle and back plate; Brugmann placed it in phase $3 \mathrm{~b}$, dating it to the second half of the sixth century.

Plot $\mathrm{F}$ was defined by the density of its intercutting graves and by the degree of intercutting. Unlike plot J-K, many graves obliterated those of previous generations. Perhaps the ethos among this community focused on the immediate generation, and not on generations of particular antecedents. The density of burial created an aesthetic space and it highlighted the closeness of burial, perhaps a closeness of relationships within the community (Wiseman, 2015). It was an aesthetic that was particular to this plot and one that could be returned to, with the intention of telling stories, and retelling them in the funerals of others. This plot was a 
palimpsest and the rewriting, destruction and moulding of that space allowed the community to reinvent itself in its narrative creation. Just as with plots A and J-K, the space itself was important, and it was structured and shaped by each new generation for themselves, and their children, but this structuring of the internal plot space was not seen in all of the plots at Dover Buckland. Plots G, H and I were contemporary with A, F and J-K but contained fewer datable graves, and less internal organisation.

Plot $\mathrm{G}$ was the largest of these less-structured plots. Just six graves were tightly dated. Inhumations 306 and 308 were the earliest and both contained A1 beads, suggesting that they were interred around AD 450-530 (Figure 3.17). Birte Brugmann placed graves 281, 290, 334 and 335 into these earlier phases. Grave 290 contained a button brooch, and graves 334 and 335 contained buckles, whereas grave 281 contained a richer assemblage which included a small square-headed brooch and a great square-headed brooch, placing the four graves within phase 1 (AD 480-530). Graves 323 and 363 were dated to the mid-sixth century; grave 323 was a weapon burial with a SP2b spearhead and a SB2B3 shield boss, and dated to AD 525-70. Burial 363 was also a weapon burial, with an SP2-B1a3 spearhead; Brugmann dated it to her phase $3 \mathrm{a}$, the latter half of the mid-sixth century (AD 550-80), because it cut grave 311 . Burial 327 was dated to phase 2 on the basis of a buckle. On the southern edge of the plot, burials 333 and 335 were both dated by Brugmann to phases 1-2 on the basis of their buckles; they may date to AD 510-60.

On the opposite side of the plot, northern grave 302 contained a buckle and an arrowhead, whereas southern grave 336 contained a buckle and beads. Both were dated by Brugmann to the latter half of the sixth century. One grave, 303, dated to the later-sixth or seventh century on the basis of B2/C beads dating it to AD 580-720. Notably, these graves contained fewer goods than those in plot $\mathrm{F}$, and they were also distributed evenly around the plot. A few graves intercut, but unlike plot $\mathrm{F}$ these were not concentrated in the central spaces of the plot.

Plots $\mathrm{H}$ and I were like $\mathrm{J}-\mathrm{K}$, in that these were probably one not two plots, so should be H-I (Figure 3.17). The latest two burials were 256 and 319, which dated to the later-sixth or seventh centuries. Therefore, for most of the sixth century these burials would not have been present, and throughout that time this area consisted of three small/medium-sized clusters of graves, rather than a coherent plot defined by the first burials, as we have seen elsewhere at Dover Buckland. The earliest graves, to the west, were 239, 245 and 247. Grave 239 had type A1 beads, a pair of early small-long brooches and a pin, graves 245 and 247 both had A2 beads and garnet jewellery, and so these were similar to, but stylistically different from, 239, where 239 was the earliest and probably 

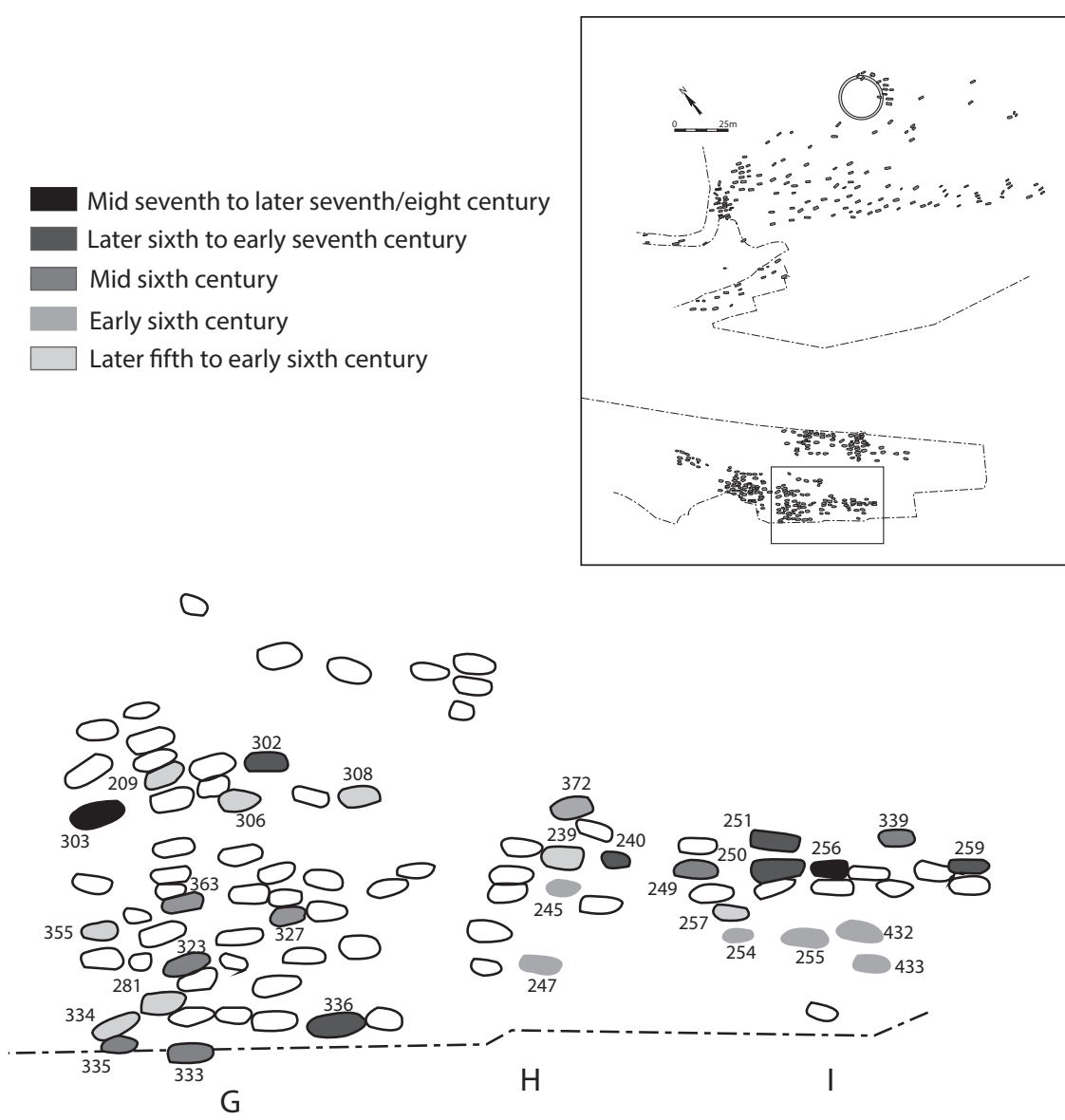

Figure 3.17 Dover Buckland: plots G, H and I in the 1994 excavation area. These three plots had less structure than the others.

fifth-century in date. Graves 254, 257 and 432 were also early, and grave 254 had A2 beads, a pin, a cone beaker, a button brooch and pair of small-long brooches. Grave 257 had A1 beads, a small-long brooch and a pin, putting it in the later-fifth or earliest-sixth century. Grave 432 had A2 beads, a cone beaker and a pin. Burials 255 and 433 were also earlier graves, and 255 contained a small square-headed brooch, a great square-headed brooch and a button brooch, which chronologically put it in into the first half of the sixth century. Grave 433 contained an openwork animal brooch of similar date. Even these earliest graves can be phased by artefact style.

The later graves were to the north-east, with mid-sixth-century burials 249, 339 and 372, where 249 was a weapon burial which contained 
an SP2-b1b spearhead (AD 510-70). Grave 339 was female-gendered with A2b beads dating to AD 530-80. Burial 372 was a wealthy femalegendered grave with a great square-headed brooch, an inlaid disc brooch and a claw beaker. Graves 250, 251 and 259 were of the later-sixth century. Grave 250 contained B1 beads, dating to AD 555-80, and 251 was male-gendered and contained an SP3-a spear, which probably dates the grave to AD 550-80. These two burials might well have felt like the middle of this group of graves when interred. Burial 259 by contrast was on the eastern edge and cut 260. It was a weapon burial with an SP2-a2a spearhead, dated to AD 550-615.

Grave 240 was later-sixth or seventh century in date, and was interred with a distinctive SP4 leaf-shaped spearhead with the socket longer than the blade. This grave might also have felt very central when interred. Grave 256 was another distinctive weapon burial found with a large SP1-a5 spear dating to the seventh century. It was truncated by 340, another male-gendered grave. Area $\mathrm{H}-\mathrm{I}$ had some of the earliest graves in the cemetery, and some early wealthy female-gendered inhumations which outnumbered the later male-gendered weapon burials, but it remained largely dispersed until the very end of its use. There was no core, and there were no barrows. As we have seen, the earliest graves clustered in two groups and it seems that the later graves were buried around them with a loose chronological character that was not dissimilar to the plot organisation at Sewerby. However, in this group of graves at Dover Buckland the latest graves defined what was for them the middle, almost as if they were redefining the organisation with the location of latest graves. Certainly plot $\mathrm{H}-\mathrm{I}$ was distinctive in that there was not the same importance placed on individuals, as seen in $\mathrm{J}-\mathrm{K}$, or on a central area, as seen in plot F. For the most part the graves in H-I were wealthier than those in plot $G$, but what is interesting is the changing nature of them, from wealthy female-gendered graves to a mixture of male and female and then male-gendered weapon graves. Perhaps this change was seen in the lived population who used this area. The inconstancy in the gender of the wealthy burials from generation to generation of the mortuary population might suggest a lack of stability in the lived population, and could help explain the absence of structure in the plot.

From the 1951 excavation, plot $C$ was notable in a number of ways. The first was that it was positioned adjacent to and around a Bronze-Age round barrow and ring ditch (Figure 3.18). The graves respected the ditch and used it to structure their location. The second is that the burials here started at a later date than in the other plots we have discussed, and the plot was in use for a shorter period of time. Grave 65 was probably the earliest datable grave; it contained an SX-1c seax dated AD 525-70, and an SP2-b1a4 spearhead. Brugmann placed the burial in her phase 3 
Mid seventh to later seventh/eight century

Later sixth to early seventh century

Mid sixth century

Early sixth century

Later fifth to early sixth century
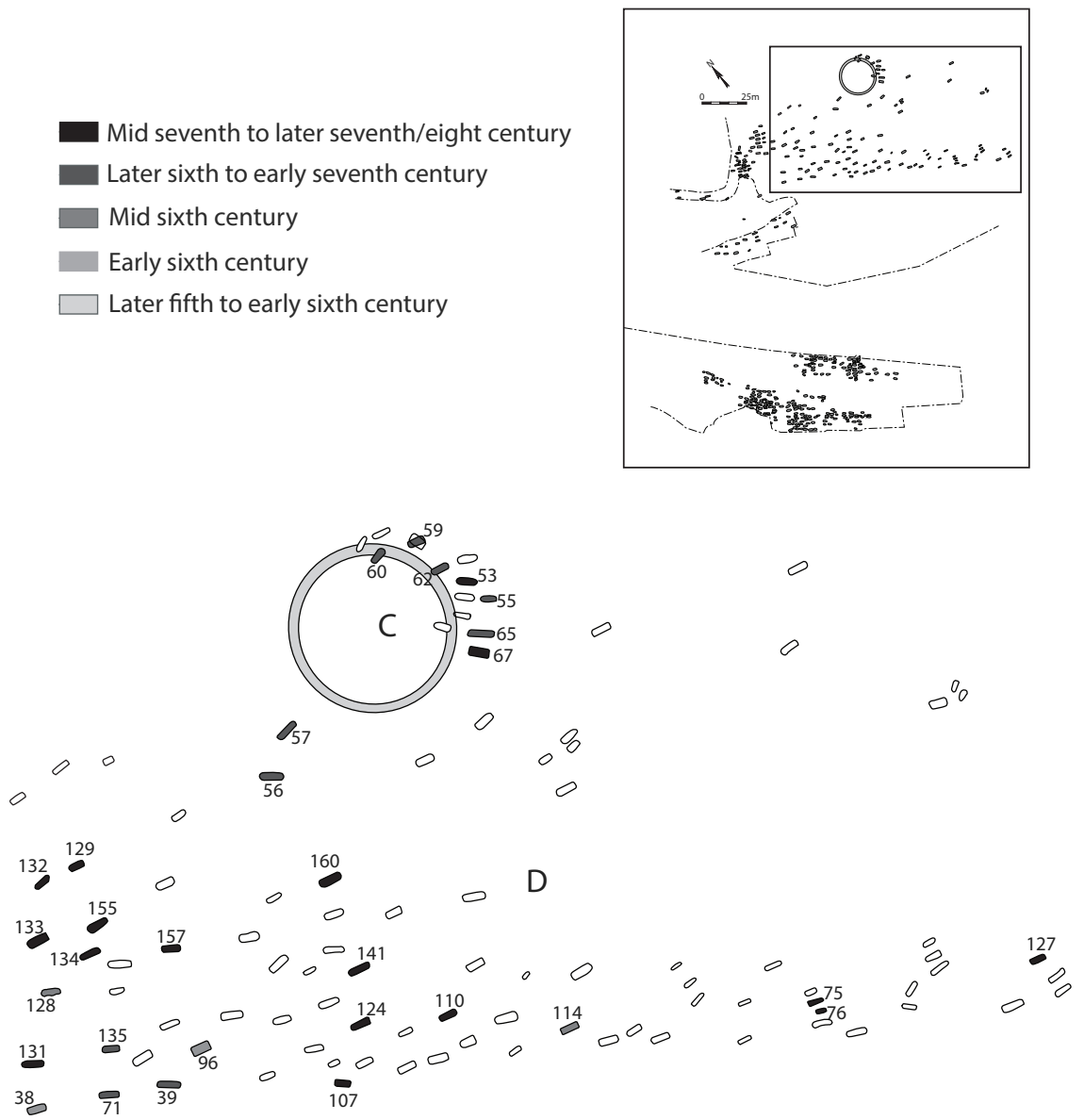

Figure 3.18 Dover Buckland: plots C and D in the 1951 excavation area. Plot C largely consisted of contemporary graves situated around an earlier barrow. Plot D consisted of a dispersed group of graves dating to the last phases of activity. Its earliest burials were found to the north.

(AD 550-600 or later). This probably suggests that this grave dated to after AD 550, perhaps to the decades either side of AD 570, which means that the spearhead was probably an old or inherited object when it was deposited. Female-gendered grave 59 also dated to the second half of the sixth century, and with B1 beads and a BR2-b3 brooch had similar dates to grave 65 . Interestingly, grave 59 cut grave 58 , obliterating part of it; if 58 was contemporary with the foundation of the plot (i.e. grave 65) this might imply that grave 59 fell later in this range. Grave 62 contained B1 beads, giving it a date around AD 570 and making it contemporary with these examples. Later graves included 55 and 60, 
which were both of female-gendered individuals with $\mathrm{B} 2$ beads, dated to AD 580-650. Similarly, graves 53 and 67 both included B3 beads, dated to AD 650-720. A male-gendered weapon burial, grave 61, unfortunately was undated. There was little obvious structure to these graves, and more of them seem to have been female-gendered than male. Interestingly, graves 56 and 57 were opposite the graves attributed to plot $\mathrm{C}$, across the other side of the barrow ditch. They were not physically associated with plot $\mathrm{C}$, but they were chronologically contemporaneous. These burials were also male-gendered weapon burials, a category of grave that was otherwise distinctly absent from the datable burials in plot C.

Just to the south of plot $\mathrm{C}$ was a small cluster of graves referred to as 'Dvii' in Chapter 2, Figure 2.9, of this book, and as plots ' $\mathrm{N}$ ' and ' $\mathrm{L}$ ' by Evison (1994: 369). Unfortunately, these graves were not datable, but notably they did sit on a slightly different orientation to the others in the wider area D. As a result they seemed to have been oriented along or around the barrow ring ditch, a situation which aesthetically separated them from plot C.

Despite Evison's subdivision of these graves into different zones, area D seemed to consist of just two stylistically different groups of graves. Notably, the first of these groups consisted of the graves that Evison (1994: 369) attributed to a single plot, her plot F, with the addition of grave 128 , which were chronologically and materially different from the rest of the burials in this area. Grave 38 was the only female-gendered grave, and with A2 beads and a garnet disc brooch of BR2b3 was midsixth century in date. All of the other datable graves were male-gendered, namely 39, 71, 96a, 96b, 128 and 135, and all contained spears of the SP2 varieties. Graves 39, 71 and 96a also contained shield bosses, while $96 \mathrm{~b}$ contained a sword. Two graves, 128 and 131, and the double grave, 96 , are most easily attributed to the mid-sixth century. The rest are more easily assigned a later-sixth-century date (Figure 3.18).

The rest of area $\mathrm{D}$ was a single area with $9 \mathrm{~m}$ clustering between graves (see Chapter 1); these inhumations had noticeably fewer artefacts, and those that were datable (graves 75, 76, 107, 124, 127, 129, 132, 133, 134, 141, 155 and 160) contained beads of group C, which date very broadly between AD 650 and 720 . There was just one weapon burial, grave 114, and based on the proportions of its blade the spear interred within it was identifiable as a type SP2-a1a1 spear, dated AD 525-70. However, this weapon consisted of an odd little spike which fits the dimensions of this type, but is not otherwise consistent with weapons from this category. As a result, this spear must be considered of local manufacture and was probably contemporary with the seventh-century graves. Area D was the largest in the Dover Buckland cemetery, and it also had the latest graves with the least material culture. In this it 
resembles the last phases of Lechlade or Polhill. These area D graves contained the least material culture; this, with the wide gaps between graves, means they were probably of later-seventh-century date, making this plot unique, because most of the groups of graves and burial areas of Dover Buckland cemetery were pluralistic, containing generations of dead, whereas this one had a much 'flatter' chronology.

\section{Dover Buckland: summary}

The early Anglo-Saxon cemetery at Dover Buckland is very important for understanding the changes in behaviour found in mortuary landscapes. It was a very diverse cemetery, with ten or eleven burial areas which chronologically at least partially overlap. Plot A was small and dense, and was in use from the later-fifth/early sixth centuries through to the later-sixth or early seventh centuries. Area B may have been an extension of A, starting with a few graves in the middle-sixth century and it then included a row of five early seventh-century graves, just like Mill Hill, Deal. There were two changes to the tempo of burial, the first one around the middle/later-sixth century when the cemetery was discordant: some plots remained in use, while others were abandoned in favour of either a widely dispersed burial or a row-grave burial. The other change was in the seventh century when, for a single generation or so, a new burial form became popular: a small group was focused on a barrow, but others were buried dispersed and ordered, as if a single model was now informing decisions. That first change was complex because, at the same time as the row graves in area B were established, area D was developed too, and this consisted of a series of widely spaced weapon burials dating to the middle and later sixth century. In the last decades of the sixth century and the early seventh century, burial area C (located around a barrow) became important, and it is worth remembering at this point that the barrow had stood for some time without direct interaction from inhumations. Perhaps these new mourners were seeking to evoke a more ancient or mysterious ancestry. As the last two burials were dug in areas $\mathrm{D}$ and $\mathrm{C}$, the larger, dispersed burial area $\mathrm{D}$ became the dominant burial area in the cemetery. Into the later seventh century, area D was the last place remaining in use. It was surrounded by earlier graves and is notable because of the $9 \mathrm{~m}$ gap between each grave. Unfortunately, as the furnished burial tradition ended there was a more limited use of gravegoods, and the relative absence of finely dated material culture means that it is impossible to see any internal structuring within area $\mathrm{D}$.

The burials reported in the 1994 project (but actually excavated in the 1950s) also displayed a discordant tempo and areas E, F, G, $\mathrm{H}-\mathrm{I}$ and J-K manifested different characters. Plot J-K was identifiable 
because of its size and because it consisted of a series of small barrows that defined and highlighted the graves of particular individuals. These would have dominated the mortuary aesthetic within this plot, and they would have been visible from each of the surrounding burial areas throughout the subsequent life of the Dover Buckland cemetery. It is probably significant that they remained unmolested (see Chapter 4), which may be evidence of how these monuments were valued by the wider community across generations. Around these barrows a number of satellite graves were placed. The plot furthest to the NW, plot E, was also notable because of its relatively short lifespan; it was in use between the fifth and later-sixth centuries, with just two datable graves and a small number of satellite graves dating to the later-sixth century. Area F was equally well structured, but instead of a focus on antecedents' graves, it had a single central space where funeral parties returned over and over again for generations, even partly obliterating older graves to place the newly dead. For them the focus does not seem to have been on longevity, but on the recently dead and the immediate family. Plot F was in use between the later-fifth and early sixth centuries and was still used regularly in the later-sixth century. In area G, graves were spaced out, had fewer intercutting graves and fewer datable artefacts, but this plot too was in use from the early sixth century until the early seventh. And in plot $\mathrm{H}-\mathrm{I}$, burials persisted from the fifth century well into the seventh century. Despite having little internal coherence, this plot contained some of the wealthiest graves in the cemetery.

It is possible to see that Dover Buckland had a broad east-to-west character, but this understates the organisational complexity. Instead, this detailed review has identified a series of distinct burial areas, with burial styles or tropes which were particular to them. Each area was chronologically unique, and some may have followed on directly from others as new emphases were found for commemoration (Sayer, 2009). It is evident there were phases in activity - the first phase focused on the grave plots, and in the second phase some of these plots persisted, while some were broken down towards the later-sixth century when a new commemorative style emerged. This new style focused on weapon burial or a row of graves, or the barrow, as at Deal. In the third phase the use of the previous two burial styles came to an end, beads were among the only significant gendered artefact, and burial style became homogenised into one that favoured a well-spaced, broadly E/W orientation. Previous mortuary technologies disappeared, and burial density, plots and gravegoods declined. In this seventh-century third phase, the underlying structure of the cemetery had broken down; burials were placed $9 \mathrm{~m}$ apart, were relatively poorly furnished and were not clustered at all. Being in the cemetery still mattered to some, and a few individuals were still interred 
in the old plots. For the most part, mortuary practice at Dover Buckland seems to have standardised in the middle- to later-seventh century after two phases of complex and colourful plurality. However, we should not get too distracted by notions of religious change; although important, these later-seventh-century graves were surrounded by the barrows and burials of their pagan ancestors in a location that would have been visually evident for hundreds of years.

\section{Conclusion}

Early Anglo-Saxon cemeteries were mutable, dynamic places and each burial saw participants negotiate around issues such as the location of a grave, how a corpse should be dressed and which objects went into, or were withheld from, the grave. The orientation of the grave - along a barrow, juxtaposed with core burials or conforming to those adjacent was locally mediated and based on the expectations of mortuary participants. The result was a continually negotiated expression, which changed generation by generation because the participants were different and because the Zeitgeist changed along with people's understanding of the space. New social perspectives and contexts mediated this change (Sayer, 2010). The nature of a negotiation might depend on who contributed, who was alive, who was present and what influences they had, or were given, by their peers. An exploration of cemetery chronology can show us when and how these negotiations differed by witnessing the changing of a cemetery pattern, or the rejection of one tradition in favour of another. This cadence might manifest in a generational focus for burial and, as a result, it might allow us to explore cemetery change as related to, but not dependent on, social change. Mortuary change was the result of a changed attitude towards the individual and deceased ancestor. Such an approach can be hugely informative and may allow us to begin writing life histories, or cemetery biographies, helping to identify specific groups or identities within them (Hines and Bayliss, 2013: 560). To understand the contrasting and changing attitudes towards cemetery space it is necessary, however, to understand the pace of this change, and the complexity of the mortuary landscapes.

Early Anglo-Saxon cemeteries have been described as monocentric or polycentric sites, which is helpful, but it assumes that there were a limited number of architects (see Chapter 1). Equally, the idea of a direction of burial also assumes there was a structure, or order, to the cemetery and that this was adhered to. These are useful starting positions, but, as we have seen, cemeteries were mutable landscapes with different dynamics across plots, by phase and within individual graves. In this chapter we have seen a number of different ways to organise cemetery space. At Orpington, a 
predominantly sixth-century site, a single grave provided a central point around which generations of subsequent weapon graves, children's graves and cremations were located. This principal antecedent provided a notable narrative point, and Orpington was probably abandoned by a generation that no longer felt a connection to this individual. Equally, early/midsixth-century plots at Oakington and plot J-K at Dover Buckland were organised around key individuals. Each subsequent generation interred key members of their community under small barrows that made them visible within the plot, but also created a striking aesthetic for the cemetery as a whole. This pattern of barrow use was also seen in several sites with substantial numbers of later-sixth- and seventh-century graves, for example St Peters, Lechlade and Finglesham. As we will see in chapters 5 and 6, later graves also had a flatter chronological nature, and this flatter nature is seen in plots B or D at Dover Buckland, which had a different character from the rest of the site. The excavated plot at Sewerby also contained a chronological character. These areas could be said to have a true horizontal stratigraphy because contemporary graves were positioned together and adjacent to their predecessors, a situation that was also seen among the configuration B burials at Apple Down and within plot $\mathrm{H}-\mathrm{I}$ at Dover Buckland. Similarly, Bossut-Gottechain showed this character, but across multiple phases. Here the central burials were the earliest, and these were organised differently from the more regular later phases of burials. Importantly, at this site, the early cemetery remained relevant, becoming the historic core around which subsequent graves were placed.

Plot B at Wakerley showed a concentric pattern, one shared by the configuration A burials at Apple Down. At these sites, key individuals from successive generations were placed in a central location, a pattern also seen at Berinsfield (Sayer, 2010). The cores of plot F at Dover Buckland and plot $\mathrm{C}$ at Wakerley were comparatively densely packed. This pattern was also seen at Hatherdene cemetery, Cherry Hinton and Morning Thorpe, though not discussed in this chapter. In all of these cases, the high density of burial was paralleled with a greater degree of intercutting. In the case of the Wakerley plot $\mathrm{C}$ graves, this density was also highlighted by a greater degree of double burial (see Chapter 5). In many of the examples from Dover Buckland the later burials obliterated, or partly obliterated, previous graves. In these plots the prime narrative principle may not have been focused on key antecedents, as seen in plots $\mathrm{J}-\mathrm{K}$ and at Oakington and Orpington, but on the generation being buried. It was their peers who organised the mortuary ritual, and it was probably how those people chose to express identity within the mortuary landscape that dictated the organisational character (see Chapter 6). Among these groups of people, emphasis was placed upon their immediate ancestor, who for these types of plot seemed to be more highly valued than those 
from their deeper past. Nonetheless, a core burial area remained and this helped to reinforce and legitimise these individuals' identities.

A number of smaller sixth-century burial plots at Dover Buckland, $\mathrm{L}, \mathrm{E}$ or $\mathrm{G}$ for example, and the westernmost graves at Orpington, do not seem to have a chronological character. The groups of people using these burial areas do not seem to have placed the same aesthetic value onto the structuring of mortuary space. Perhaps they identified their connection to the past in different ways, in different places. Perhaps they did not share the same need or desire to express this part of their identity in community or public spaces.

Later-sixth- and seventh-century graves seem to have had more uniformity. At Dover Buckland, area D consisted of widely, but equally, spaced graves. A similar pattern is seen at Polhill and Lechlade, which are presented in Chapter 6. Indeed, as seen in Chapter 2, Street House, Garton Slack II and Dunstable were later-sixth- or seventh-century cemeteries which displayed regular, ordered or row-grave structures. However, this was not always the case, for Dover Buckland plots B, C and Di were later, or transitional, phases between the early/mid-sixth and seventh centuries. All of these had a much flatter chronological organisation, and this structure highlighted a number of comparable graves from the same generation, a pattern also seen at Lechlade and Finglesham.

These three transitional plots at Dover Buckland all highlight an important aspect of the site. Not all of the plots, or groups of graves, shared the same pace of change. Figure 3.19 presents a battleship-style

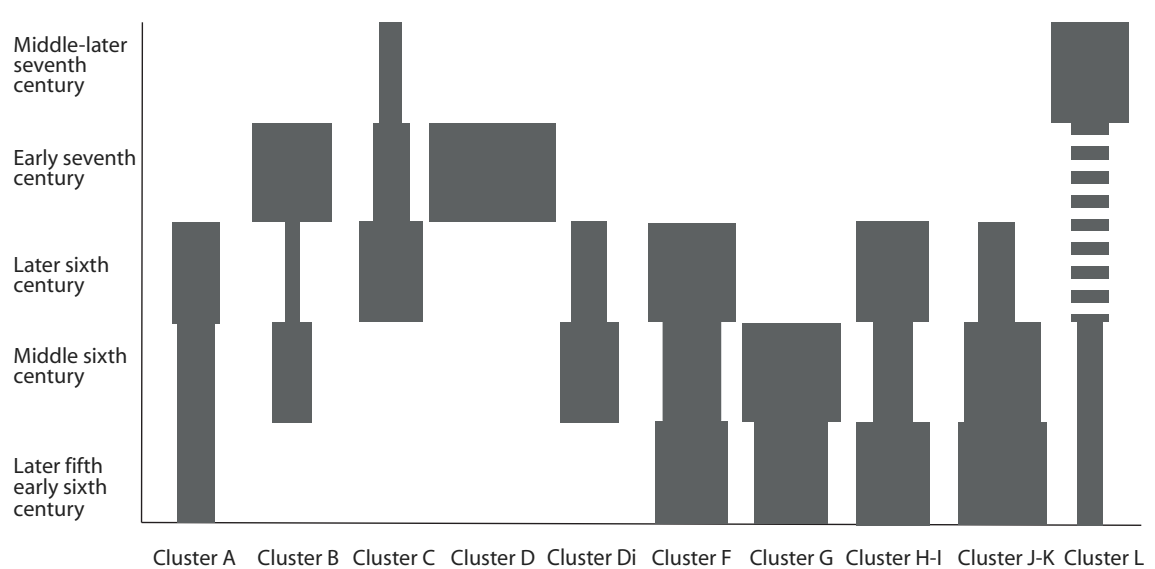

Figure 3.19 Dover Buckland: 'battleship' histogram. This shows the different chronological activity in the various plots (clusters), illustrating that these areas were not all contemporary and, importantly, that not all of the plots shared the same pace of change, some being long-lived, others short-lived. 
histogram that illustrates the changes in frequency of datable graves for each of the ten plots at Dover Buckland. Chronologically, plot G mostly received early/middle-sixth-century inhumations while four plots $(\mathrm{A}, \mathrm{F}$, $\mathrm{H}-\mathrm{I}, \mathrm{J}-\mathrm{K})$ were used predominantly between the early and later-sixth century. Plot $\mathrm{D}$ was in use between the middle- and later-sixth centuries. Plot B was used between the middle-sixth and early seventh centuries and plot $\mathrm{C}$ was in use between the later-sixth century and the end of the seventh century. Burials in plot $\mathrm{D}$ were isolated to the early seventh century, whereas the infrequent burials in area $\mathrm{L}$ were placed there for the whole period that the cemetery was in use. This pattern is notable in highlighting an important watershed between the later-sixth and seventh centuries, but it also identifies a number of other important chronological transitions around the middle-sixth and early seventh centuries. Each of these burial plots had a different style - some were densely packed, some marked by barrows, others used external features or rows of graves as part of their structure - but they also each had their own different metre or cadence. Plots $\mathrm{G}$ and J-K were used intensely and early, and then declined quickly, whereas A and L took just a few burials over a hundred or more years. This cadence was also seen at Spong Hill, where burial areas waxed and waned in importance across the life of the site, until the final phase where focus shifted to the north, and the inhumation burials.

As we have discussed here, this chronological metre may have resulted from the way that users of a particular burial space saw their past, how they interacted with their dead and how they valued, or not, the graves of their antecedents. Understanding the chronology of burial is not just a way to date graves, but to understand the context of burial. There were a number of ways to organise mortuary space, and these were the result of negotiations around differences in attitude toward the dead. Differences in these attitudes probably reflect how communities used mortuary spaces as ways to express, maintain and reproduce communal identities. These ideas are discussed further in chapters 5 and 6.

\section{Note}

1 The spears from graves 54 and 126 are of type SP2b1b and are attributed to an early phase which ended around AD 570-650. Grave 145 included a type SP2a1b2 spear and has a middle- to late-sixth-/early seventh-century range of AD 525-615 (Hines and Bayliss, 2013: 163, 485, 565-6). Grave 145 also included a shield of type SB2 - with a date between AD 525 and 570, providing a tighter date for this burial (Hines and Bayliss, 2013: 151, 458, 563). 